\title{
An Integrated Study of Heart Pain and Behavior in Freely Moving Rats (Using Fos as a Marker for Neuronal Activation)
}

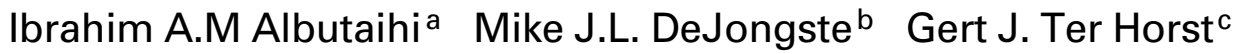 \\ aFaculty of Medical Sciences, ${ }^{b}$ Department of Cardiology, Thoraxcenter, and 'Department of Biological Psychiatry, \\ University Hospital of Groningen, Groningen, The Netherlands
}

\section{Key Words}

Angina pectoris · Bradykinin · Capsaicin · Pain · Vagus nerve

\begin{abstract}
The awareness in specific brain centers of angina pectoris most often results from ischemic episodes in the heart. These ischemic episodes induce the release of a collage of chemicals that activate chemosensitive and mechanoreceptive receptors in the heart, which in turn excite receptors of the sympathetic afferent pathways. Ascending pain signals from these fibers result in the activation of the brain centers which are involved in the perception and integration of cardiac pain. Cytochemical studies of the nervous system provide the opportunity to identify these areas at the cellular level. In the present investigation, cardiac nociception was studied in the brains and the spinal cords of rats, using Fos protein as a marker of neuronal activation, following the application of pain-inducing chemicals to the heart. Induction of myocardial pain in conscious rats was achieved by infusion of bradykinin $(0.5 \mu \mathrm{g})$ or capsaicin $(5 \mu \mathrm{g})$ into the pericardial sac. During pain stimulation, the rats demonstrated pain behavior, in conjunction with alterations in heart rate and blood pressure. The cerebral Fos expres-
\end{abstract}

sion pattern was studied $2 \mathrm{~h}$ after pain stimulation. In contrast to the control group, increased Fos expression was found following the use of both capsaicin and bradykinin in a variety of areas of the brain. Bradykinin, but not capsaicin, induced Fos expression in the upper thoracic and upper cervical spinal cord; these segments are the sites where cardiac sympathetic fibers terminate. This finding suggests that these two chemicals use two different pathways, and provides extra evidence for the role of the vagus nerve in the transmission of cardiac nociception. Different cerebral areas showed an increase in the c-fos activity following pericardial application of paininducing chemicals. The role of these cerebral areas in the integration of cardiac pain is discussed in relation to the identified pathways which transmit cardiac pain.

Copyright $(2004$ S. Karger AG, Basel

\section{Introduction}

Patients with ischemic heart disease often seek medical care when they experience symptoms of chest pain, generally referred to as angina pectoris. Both physical exercise and mental stress can induce angina in patients with ischemic heart disease. The 'anginal warning signal' is propagated to the brain through afferent neural pathways [1].

\begin{tabular}{ll}
\hline KARGER & ( 2004 S. Karger AG, Basel \\
Fax +4161306 1234 & 1424-862X/04/0135-0207\$21.00/0 \\
$\begin{array}{l}\text { E-Mail karger@karger.ch } \\
\text { www.karger.com }\end{array}$ & $\begin{array}{l}\text { Accessible online at: } \\
\text { www.karger.com/nsg }\end{array}$
\end{tabular}

Mike J.L. DeJongste, MD, PhD

Department of Cardiology, Thoraxcenter, University Hospital of Groningen PO Box 30.001

NL-9700 RB Groningen (The Netherlands)

Tel. +31 50361 2812, Fax +31 50361 4884, E-Mail M.J.L.De.Jongste@thorax.azg.nl 
Recruitment of these afferent pathways during ischemic challenges arises from the local release of a variety of compounds, including potassium, lactate, adenosine, bradykinin and prostaglandins $[2,3]$, which are able to sensitize high-threshold nerve endings in the heart [4]. The induction of an inflammatory response further sensitizes afferent nociceptors (i.e., the threshold of the high-threshold fibers becomes lower) $[4,5]$. As a result, it is unlikely that one chemical will induce anginal pain in vitro. We used bradykinin or capsaicin. Since these two algesic substances employ different actions, they can be used to specify the neural centers that are involved in the perception and integration of cardiac pain more precisely. Bradykinin is a mediator of inflammatory pain [6] released following ischemia in the myocardium [7], and is used as the chemical of choice to produce nociceptive responses. Capsaicin has become a valuable substance for revealing the function of the afferents. A selective site of action of capsaicin on polymodal-type nociceptors of the $\mathrm{C}$ and $\mathrm{A}$ delta fibers was described by single unit studies, both in cutaneous nerves and in nerve branches innervating the heart and the great vessels [8-11].

Intermittent or permanent occlusion of a coronary artery stimulates chemical and mechanical cardiac receptors which excite sympathetic and vagal afferent fibers. Both types of fiber are responsible for the first part of the transmission of afferent information following ischemic challenges from the heart, and ultimately give rise to the awareness of pain in the cognitive centers of the brain.

Neuroimaging techniques have enabled researchers to identify cerebral activation patterns during angina pectoris. However, these techniques provide only rough information about different areas in the CNS involved in cardiac pain. Cytochemical studies of the nervous system provide the opportunity to identify these areas more precisely at a cellular level. Therefore, we investigated the different brain centers involved in the perception and integration of cardiac pain by administering noxious compounds into the pericardial sacs of conscious rats [12]. Cerebral Fos protein was used as a marker of neuronal activation. Fos is a transiently expressed immediate early gene protein used to characterize CNS activity patterns after painful stimulation. The validity of the use of c-fos as a marker of neuronal activity has been established previously [13-18].

The use of animal models enabled us to obtain an image of the cytoarchitecture and neurochemistry of cardiac pain processing circuitry. Moreover, such models provide possibilities to test the physiological and behavioral consequences of pain processing.

\section{Materials and Methods}

\section{Animals}

Male Wistar rats (250-300 g body weight) were housed in separate cages $(40 \times 30 \times 30 \mathrm{~cm})$ in a temperature-controlled environment with a light-dark regimen ( $12 \mathrm{~h}$ dark period), immediately after the arrival in the laboratory. Harlan (Zeist, The Netherlands) supplied the animals. Food (standard laboratory rat chow) and water were ad libitum. After a 3-day acclimatization, a permanent pericardial sac catheter was implanted in all animals. Postsurgical recovery was 7 days and an additional 7 days for animals supplied with telemetric (Data Sciences Int.) blood pressure and heart rate monitoring devices. Apart from the observed weight gain, reappearance of a diurnal cardiovascular rhythm was an indication of the recovery of the animals after 7 days.

The local Animal Bio-Ethics Committee (DECnr. 1189) approved all procedures. Since the experiments were conducted in conscious rats, the number of animals used was minimized, conforming to the guidelines for the use of awake animals in experimental pain research [19] of the International Society for Pain Research.

\section{Surgery}

The rats were preanesthetized in a Perspex chamber $(10 \times 20 \times$ $10 \mathrm{~cm}$ ) with a mixture of halothane, nitric oxide, and oxygen. At an appropriate level of anesthesia, the animals were removed from the box to be intubated with a plastic 14-gauge tube $(21 \times 45 \mathrm{~mm})$, and connected to a ventilator (MK2 Infant ventilator, Loosco, Amsterdam, The Netherlands) that supplied the same anesthetic. Then the animals were prepared for the surgery. The skull was cleaned for the fixation of the cannula and the abdominal-thoracic area for an abdominal-diaphragmatic route of approach to the pericardial sac. A hole was punched in the pericardial sac to allow the insertion of the silicon catheter (diameter outside $100 \mu \mathrm{m}$, inside $50 \mu \mathrm{m}$ ). One centimeter of the catheter was placed in the pericardial sac and secured to the pericardial tissue and fat pads with sterile $6 / 0$ silk sutures (BV-1, Ethicon GmbH, Norderstedt, Germany). In 4 rats, the catheter was placed in the extrapericardial space to serve as a control for possible leakage effects. The catheter was tunneled to the head subcutaneously. A hypodermic needle ( 25 gauge, $0.5 \times 16 \mathrm{~mm})$, bend $90^{\circ}$, was placed on the catheter for attachment of the infusion tube. The device was fixed on the head with dental cement. The abdominal wounds were closed after securing of the catheter with tissue glue. Then the animals were detubated and placed on a heating pad for recovery.

Three rats in every experimental group were reanesthetized after 7 days for the implantation of a telemetric blood pressure recording device (Data Sciences Int., St. Paul, Minn., USA, type: TA11PAC20). In these animals, the descending aorta was exposed and clamped with a counter-weighted suture at the level of the renal artery. A hole was punched in the aorta with a sharp hypodermic needle approximately $5 \mathrm{~mm}$ proximal of the decussation. The tip of the cannula of the recording device was inserted into the descending aorta and fixed with tissue glue. The telemetric device $(2.5 \times 1 \times$ $1 \mathrm{~cm}$ ) was placed in the abdomen and then the wounds were closed.

\section{Experimental Procedure}

The animals were handled daily to reduce stress associated with the preparation of the experiment. Thirty minutes before the start of the infusion of the noxious compound, the animals were connected to the infusion pump (CMA 100 Carnegie Medicine) and placed in 
the observation cage $(30 \times 25 \times 30 \mathrm{~cm})$. The behavior was recorded on video from -30 to $60 \mathrm{~min}$ after the start of the infusion. 'Pain' behavior was analyzed with dedicated software (Observer 3.0, Noldus Information Technology, Wageningen, The Netherlands). Acute pain was generated with $50 \mu \mathrm{l}$ of a noxious compound, delivered at a speed of $2 \mu \mathrm{l} / \mathrm{min}$ (CMA 100, Carnegie Medicine).

All animals were terminated after $2.5 \mathrm{~h}$ with an intraperitoneal injection of a $6 \%$ sodium pentobarbital solution $(2 \mathrm{ml} / \mathrm{kg})$. After transcardial perfusion with heparinized saline and a $0.2 \mathrm{M}$ phosphate-buffered $4 \%$ paraformaldehyde solution ( $\mathrm{pH} 7.4$ ), the brain and spinal cord were removed, postfixed in the same fixative solution overnight, and then placed in phosphate-buffered saline solution containing $0.1 \%$ sodium azide at $4{ }^{\circ} \mathrm{C}$. After cryoprotection in $30 \%$ $0.2 M$ phosphate-buffered sucrose solution (pH 7.4), serial $40-\mu \mathrm{m}$ coronal sections of the brain and spinal cord were prepared on a cryostat microtome and collected in $0.02 M$ phosphate-buffered saline (pH 7.4) with $0.1 \%$ sodium azide and stored at $4{ }^{\circ} \mathrm{C}$.

\section{Immunohistochemistry}

The immunocytochemical procedure for visualization of Fos protein expression has been described previously [20]. In brief, free floating sections were preincubated in a $0.02 \mathrm{M}$ potassium phosphate-buffered saline solution (KPBS; $\mathrm{pH} 7.4$ ) containing $2 \%$ normal rabbit serum, and $2 \%$ bovine serum albumin during $4 \mathrm{~h}$. Thereafter, the free-floating sections were incubated with polyclonal sheep antic-Fos (1:2,000; OA-11-824) solution in KPBS containing 2\% normal rabbit serum, $2 \%$ bovine serum albumin and $0.3 \%$ Triton $\mathrm{X}-100$. After overnight incubation at room temperature and thorough washing with KPBS, the sections were incubated with biotinylated rabbit anti-sheep IgG (1:800 Pierce) solution in KPBS during $4 \mathrm{~h}$. Following several rinses with KPBS, the incubation was continued in a solution containing peroxidase-labeled avidin-biotin complex (Vector Labs.) during $4 \mathrm{~h}$. The presence of peroxidase was revealed with a $0.05 \%$ 3,3-diaminobenzidine (Sigma), 2.5\% nickel ammonium sulfate, $0.04 \%$ ammonium chloride and $0.005 \%$ hydrogen peroxide solution. The diaminobenzidine reaction was stopped after $20 \mathrm{~min}$. Then, the sections were washed in KPBS and mounted with a gelatin-chrome alum solution. After dehydration in graded ethanol solutions and xylene, the material was embedded with Depex.

\section{Quantifications}

The number of Fos-positive cells was quantified in a number of selected brain regions (fig. 3$)$ with an ocular grid $(5 \times 5$ squares; $400 \times 400 \mu \mathrm{m}$ at a magnification of $\times 125$ ). Different rostro-caudal levels were defined with the stereotaxic atlas of Swanson [21]. The number of labeled cells was expressed as left-right mean value, unless stated otherwise.

\section{Statistics}

One-way ANOVA with a Student-Neuman Keuls multiple comparison method was used to test the effects of the treatments. Pairwise comparisons were performed with a Student $t$ test. The data were analyzed with the statistical software package Sigmastat ${ }^{\circledR}$ (Jandel Scientific, San Rafael, Calif. USA). $p<0.05$ was considered significant.

\section{Drugs}

Bradykinin (Sigma, St. Louis, Mo., USA) was dissolved in saline to a concentration of $100 \mu \mathrm{g} / \mathrm{ml}$ stock solution. The bradykinin stock was diluted in $0.2 \%$ Evans blue saline 1:10, of which $50 \mu \mathrm{l}$ were administered into the pericardial sac (effective amount $0.5 \mu \mathrm{g}$ bradykinin). Capsaicin was mixed with $10 \%$ Tween $80,10 \%$ ethanol, and $80 \%$ saline to create a stock solution of $1 \mathrm{mg} / \mathrm{ml}$. Fifty microliters of a $1: 10$ diluted stock solution in $0.2 \%$ Evans blue saline was administered (effective amount $5 \mu \mathrm{g}$ capsaicin). These dosages caused nociceptor activation in various experimental designs [6, 20, 22]. Pilot experiments showed that these amounts induced significant behavioral responses in our design. Evans blue was added to the solutions for postmortem inspection of the filling and/or leakage of the pericardial sac [20].

\section{Results}

\section{Behavior}

The rats showed a typical pain behavior irrespective of the noxious compound that was administered. Increased exploration, characterized by escape behavior and scratching of the chest, forepaw, and neck area, preceded a long-lasting immobilization in a typical position both after administration of bradykinin and capsaicin (44 \pm $9 \%$ and $73 \pm 3 \%$ of the observation time for bradykinin and capsaicin, respectively). During the immobilization, the chest was pressed firmly to the bottom of the cage and often the forepaws and hindpaws were extended. Delayed bradykinin-induced immobilization, which started after $10 \mathrm{~min}$, explains the significant behavior differences between the capsaicin and bradykinin group with respect to the time spent on immobilization, exploration, and wake behaviors (fig. 1). The different behavioral responses also illustrate that capsaicin not only can generate immediate, but also stronger adverse effects than bradykinin. Administration of the noxious compounds into the chest caused the same behavioral responses and typical pain behavior (59 $\pm 17 \%$ of the observation time). Saline infusions into the pericardial sac never generated immobilization or pain behavior.

\section{Cardiovascular Responses}

After the attachment of the microinfusion pump, blood pressure and heart rate values returned to baseline (heart rate: $345-370$ beats/min and mean arterial pressure: $100-110 \mathrm{~mm} \mathrm{Hg}$ ) in approximately $10 \mathrm{~min}$. Bradykinin administration was followed by an immediate, but nonsignificant rise of heart rate, in parallel with a change of the behavior. Heart rate was elevated for $1 \mathrm{~h}$ (fig. 2A) and then followed by a slight decrease. Capsaicin caused, despite a strong behavioral response, a slight decrease in heart rate during the first $20 \mathrm{~min}$ (fig. 2C). Ten minutes after the pump was switched off, the heart rate reached a maximum of $430 \pm 25$ beats $/ \mathrm{min}$. 
Fig. 1. Behavioral responses of animals receiving saline, bradykinin and capsaicin into the pericardial sac. The data are expressed as percentage of time spent during the $35 \mathrm{~min}$ of observation following infusion. Behavioral responses of animals receiving bradykinin in the extrapericardial space (chest) are also provided. a $\mathrm{p}<0.05$ : a significant difference from control. ${ }^{b} \mathrm{p}<0.05$ : a significant difference from bradykinin-treated animals. n.s. $=$ Behavior not shown.

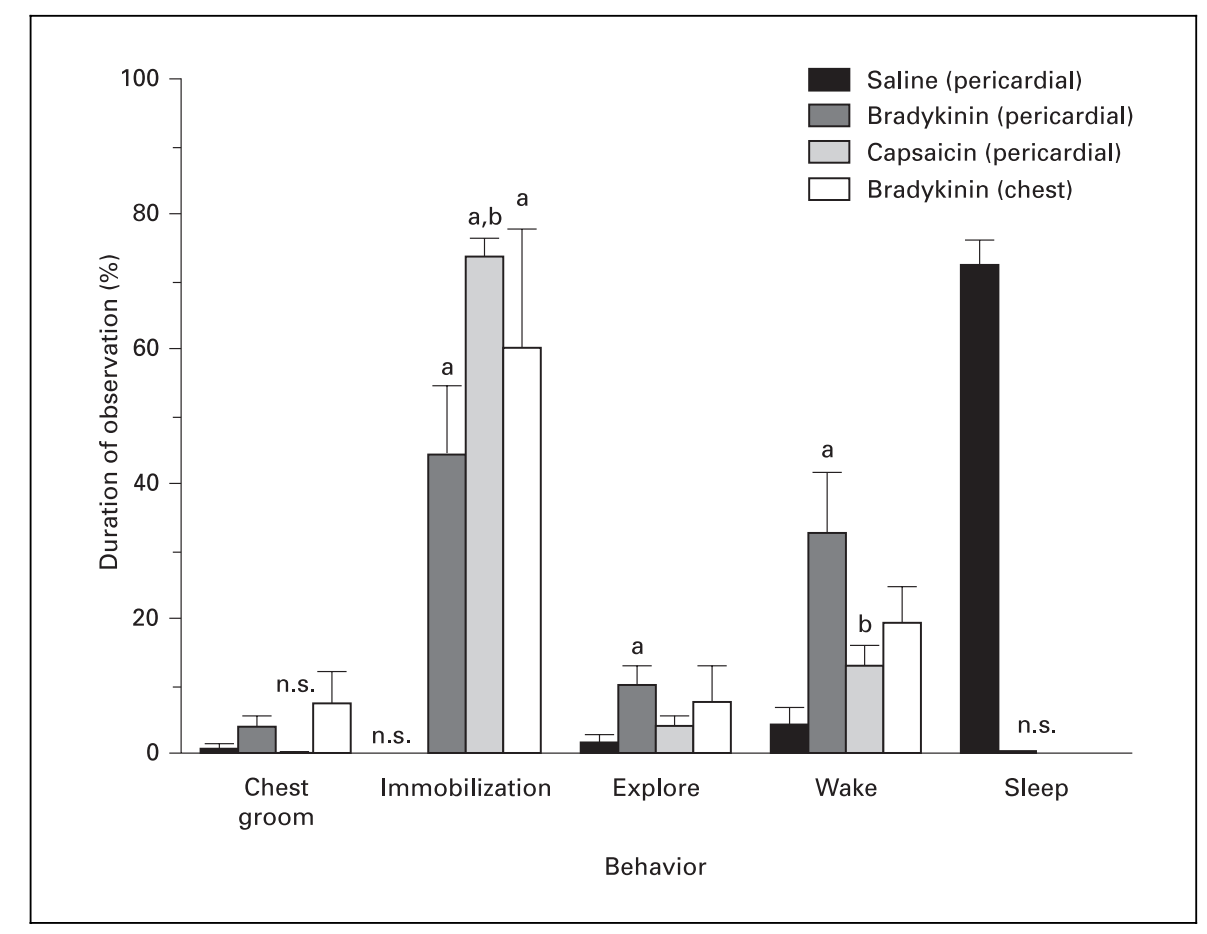

Blood pressure effects of pericardial capsaicin administration were more pronounced (fig. 2C, D). Three minutes after the start of the infusion, capsaicin generated biphasic hypertension. The mean arterial pressure was significantly elevated between 7 and 12 min (baseline mean arterial pressure $105 \pm 7 \mathrm{~mm} \mathrm{Hg}$ to peak mean arterial pressure $131 \pm 9 \mathrm{~mm} \mathrm{Hg}$ ) and again between 56 and $70 \mathrm{~min}$ (peak of $119 \pm 3 \mathrm{~mm} \mathrm{Hg}$ ). Bradykinin did not generate significant changes of mean arterial pressure.

Saline infusions into the pericardial sac were not associated with significant alterations of blood pressure and heart rate (data not shown), which is in line with the observed undisturbed behavior. Control infusions of the noxious compounds into the chest generated cardiovascular responses that were compatible with the pericardial sac infusions (fig. 2).

\section{Bradykinin-Induced Fos Expression}

The distribution of Fos-labelled cells in the nervous system after pericardial administration of saline and bradykinin is presented schematically in figure 3. Column 3 indicates the sites that were quantified.

Increased Fos immunoreactivity (Fos-ir), compared with the saline-induced expression, was found in the preand infralimbic cortex, the shell of the nucleus accumbens, and the dorsal and ventral agranular insular cortex (fig. 3A). Regionally, the primary motor cortex and the jaw area of the primary sensory cortex showed an increased Fos-ir. The anterior cingulate cortex (Acg), the ventrolateral caudate putamen, and the olfactory tubercle all showed a moderate increase. Rostral hypothalamic areas showing altered Fos-ir were the ventral bed nucleus of the stria terminalis, and the medial, ventral and ventrolateral parts of the medial preoptic nucleus. The most impressive increase in Fos-ir in the forebrain was found in the posterior insular cortex (fig. 4F), in the posterior agranular and the granular fields (fig. 3B, C). In the sensory and motor cortices and the retrosplenial cortex, we noted a regionally increased Fos-ir. Other areas exhibiting a significant Fos-ir were the central amygdala, the paraventricular hypothalamic nucleus (PVN; fig. 5B), the dorsal and dorsomedial hypothalamus, the perifornical area and the medial part of the lateral hypothalamus. The medial amygdala, the medial part of the zona incerta, the thalamic reuniens and rhomboid nuclei, the centromedial, the paraventricular, and the centrolateral thalamic nuclei all showed a slightly increased Fos expression. A significantly increased Fos-ir was found in the auditory, the temporal association, and the ectorhinal cortices, as well as in the medial part of the lateral amygdaloid nucleus. Interestingly, neither saline nor bradykinin induced Fos-ir in the rostral part of the ventral posterolater- 

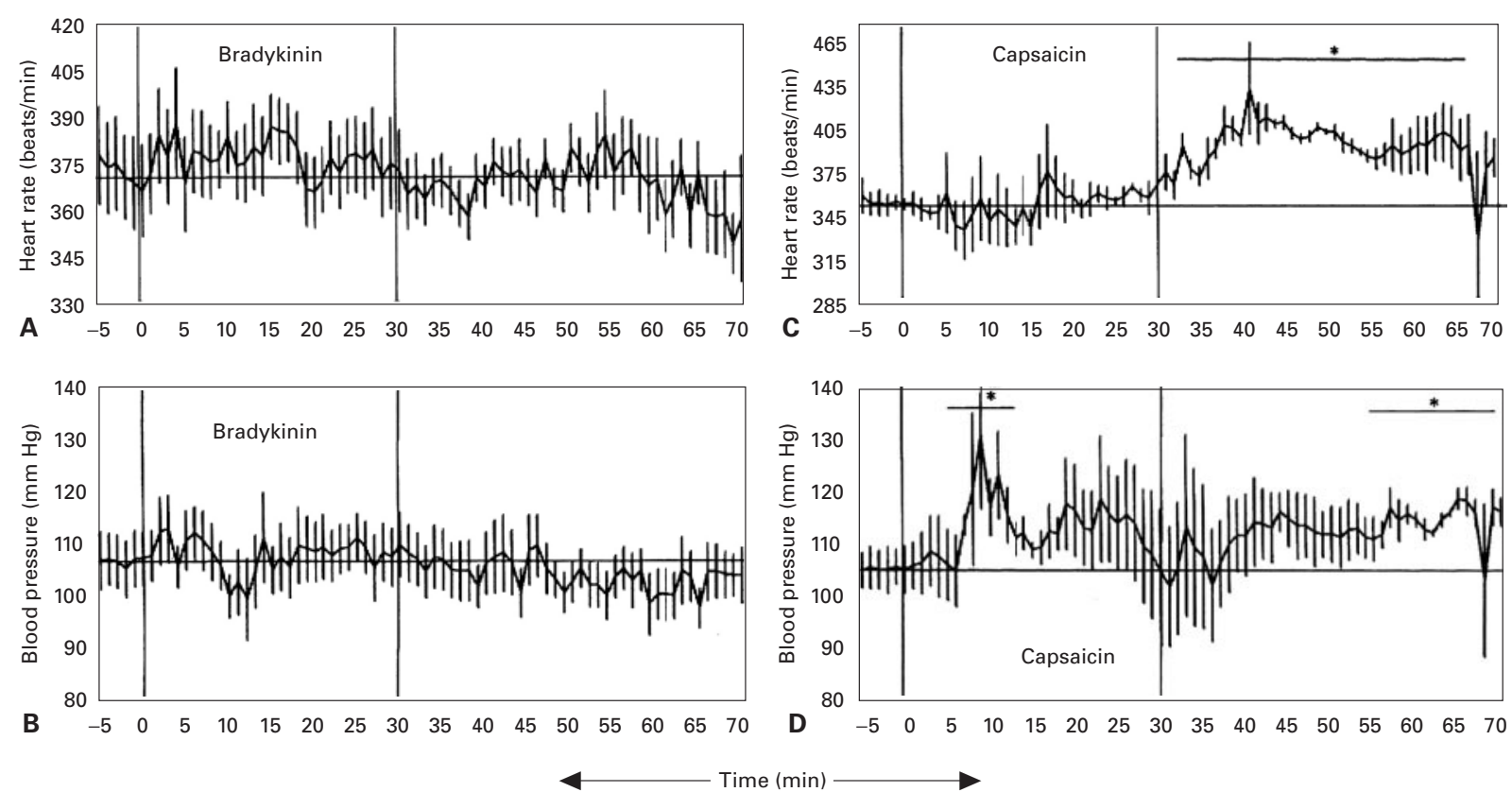

Fig. 2. Graphs showing effects of the pericardial bradykinin $(n=3)$ and capsaicin $(n=3)$ infusions on heart rate and blood pressure of conscious rats. Significant increases from baseline levels are indicated with an asterisk $(p<0.05)$. A Heart rate (beats/min + SEM) after pericardial bradykinin infusion. B Blood pressure $(\mathrm{mm} \mathrm{Hg}+\mathrm{SEM})$ after pericardial bradykinin infusion. C Heart rate (beats/min + SEM) after pericardial capsaicin infusion. D Blood pressure $(\mathrm{mm} \mathrm{Hg}+\mathrm{SEM})$ after pericardial capsaicin infusion.

al thalamic nucleus and in the reticular thalamic nucleus (fig. 3D).

In the posterior diencephalon (fig. 3E), the parvocellular part of the subparafascicular nucleus (SFPC), the ventral part of the ventroposterolateral (VPLpc) and ventroposteromedial (VPMpc) thalamic nucleus, the adjoining dorsal part of the zona incerta and the posterior thalamic nucleus (fig. 4A) were all Fos positive after bradykinin administration into the pericardial sac. The number of Fos-ir cells was increased in the intergeniculate leaflet and the parvocellular ventrolateral geniculate nucleus and subgeniculate nucleus, and in the pretectal area, the supramammillary nucleus, the parafascicular thalamic nucleus, and the dorsolateral part of the posterior lateral hypothalamus. Fos expression in cortical fields, at this rostro-caudal level, was moderately increased in the retrosplenial gyrus, the secondary visceral cortex, the parietal association cortex, and the primary and secondary auditory fields. The perirhinal, entorhinal, and ectorhinal cortex were not affected, but the posteromedial amygdalohippocampal area showed a small increase in Fos-ir.
In the midbrain, Fos expression was increased in various subregions of the periaqueductal gray (PAG), in particular the dorsomedial rostral PAG, the dorsolateral and lateral medial PAG (fig. 6A, B), and the lateral and ventrolateral caudal PAG (fig. 3F, G). Other areas showing increased Fos-ir at this level were the peripeduncular nucleus, the triangular part of the posterior thalamic nucleus, the ventrolateral part of the anterior pretectal nucleus, and the medial part of the superior colliculus. A low to moderate increased Fos-ir was found in the retrosplenial gyrus, the secondary visceral field, and in selective parts of the auditory and the temporal association cortex. Bradykinin increased Fos expression in the ventrolateral pontine reticular formation. The Kölliker-Fuse nucleus, the pons, the locus coeruleus (LC), the dorsal and lateral parabrachial nuclei, the ventrolateral reticular A5 area, the raphe magnus and the lateroventral periolivary nucleus all showed increased Fos-ir at the pontomedullary level. Regionally, the treatment affected Fos-ir in the principal spinal trigeminal nucleus (fig. $3 \mathrm{H}$ ) and the ventral cochlear nucleus. 


\begin{tabular}{|c|c|c|c|}
\hline \multicolumn{4}{|c|}{ Abbreviations used in figures $3,4,6$, and 7} \\
\hline 5 & motor trigeminus nucleus & $\mathrm{MdV}$ & ventral medullary reticular nucleus \\
\hline 7 & facial nucleus & $\mathrm{ml}$ & mediolateral thalamus \\
\hline 10 & vagal nucleus & $\mathrm{mg}$ & medial geniculate nucleus \\
\hline 12 & hypoglossus nucleus & Mve & medial vestibular nucleus \\
\hline $\mathrm{Acb}$ & accumbens nucleus & NTS & solitary tract nucleus \\
\hline Acg & anterior cingulate cortex & P5 & principal spinal trigeminal nucleus \\
\hline $\mathrm{AI}$ & agranular insular cortex & PAG (pag) & periaqueductal gray \\
\hline AIP (aip) & posterior agranular insular cortex & $\mathrm{Pb}$ & parabrachial nucleus \\
\hline $\mathrm{AMB}(\mathrm{amb})$ & ambiguus nucleus & PCRt (pcrt) & parvocellular reticular formation \\
\hline Amyg & amygdala & $\mathrm{PF}$ & perifascicular thalamus nucleus \\
\hline APT & anterior pretectal nucleus & Pir & piriform cortex \\
\hline $\mathrm{Au}$ & auditory cortex & PL & prelimbic cortex \\
\hline BST & bed nucleus stria terminalis & Pn & pons \\
\hline $\mathrm{cc}$ & cingulate cortex & $\mathrm{PnO}$ & oral pontine nucleus \\
\hline $\mathrm{CM}(\mathrm{cm})$ & centromedial thalamus nucleus & Po (po) & posterior thalamus nucleus \\
\hline $\operatorname{cnf}$ & cuneiform nucleus & PRF & pontine reticular formation \\
\hline $\mathrm{Cpu}$ & caudate putamen & Py & pyramidal tract \\
\hline $\mathrm{cp}$ & caudate putamen & $\mathrm{RE}$ & reuniens thalamic nucleus \\
\hline $\mathrm{Cu}(\mathrm{cu})$ & cuneate nucleus & RMG & raphe magnus nucleus \\
\hline $\mathrm{DC}$ & dorsal cochlear nucleus & RSA & retrosplenial cortex \\
\hline di & dysgranular insular cortex & RtT & reticular tegmental nucleus \\
\hline $\mathrm{dr}$ & dorsal periaqueductal grey & RVL & rostroventrolateral medulla oblongata \\
\hline Dtg & dorsal tegmentum & $\mathrm{S}$ & subiculum \\
\hline Ect & ectorhinal cortex & $\mathrm{S} 1$ & primary somatosensory cortex field \\
\hline Gi (gi) & gigantocellular reticular nucleus & $\mathrm{S} 1 \mathrm{BF}$ & primary somatosensory barrel field area \\
\hline gr & gracile nucleus & $\mathrm{s} 2$ & sensory optic nerve \\
\hline Hyp & hypothalamus & S5 & sensory trigeminal nerve \\
\hline $\mathrm{IC}$ & inferior colliculus & $\mathrm{SC}$ & superior colliculus \\
\hline Ihb & lateral habenula & scp & superior cerebellar peduncle \\
\hline IL & infralimbic cortex & $\mathrm{Sp} 5(\operatorname{sp} 5 \mathrm{c})$ & spinal trigeminal nucleus \\
\hline IML & intermediolateral cell group & $\mathrm{Sp} 5 \mathrm{c}$ & caudal spinal trigeminal nucleus \\
\hline Irt & intermediate reticular nucleus & SS & somatosensory cortex field \\
\hline Lfu & lateral funiculus & ts & tractus solitarius \\
\hline LG & lateral geniculate nucleus & V2 & secondary visual cortex \\
\hline $\mathrm{Li}$ & linear medulla nucleus & vl pag & ventrolateral periaqueductal grey \\
\hline LL & lateral lemniscus & VPL (vpl) & ventroposterolateral thalamus nucleus \\
\hline $\mathrm{LPb}$ & lateral parabrachial nucleus & vpm & ventroposteromedial thalamus \\
\hline Lrt & lateral reticular nucleus & vppc & ventroposterior parvocellular thalamic nucleus \\
\hline LS & lateral septum & $\mathrm{vm}$ & ventromedial thalamic nucleus \\
\hline LSO & lateral superior olive nucleus & ZI (zi) & zona incerta \\
\hline M1 & primary motor cortex field & II & lamina II of Rexed \\
\hline M2 & secondary motor cortex field & III & lamina III of Rexed \\
\hline $\mathrm{md}$ & dorsomedial thalamus & $\mathrm{V}$ & lamina $\mathrm{V}$ of Rexed \\
\hline MdD & dorsal medullary reticular nucleus & VII & lamina VII of Rexed \\
\hline
\end{tabular}

Fig. 3. Series of coronal hemisections of the rat brain illustrating, from rostral (A) to caudal (L), the locations of Fos-ir cells in saline- and bradykinin-treated animals. M Fos expression in the second thoracic segment is shown. Column 3 gives the names of the affected structures and indicates the location of regions in which the Fos expression was quantified (data in table 1). 


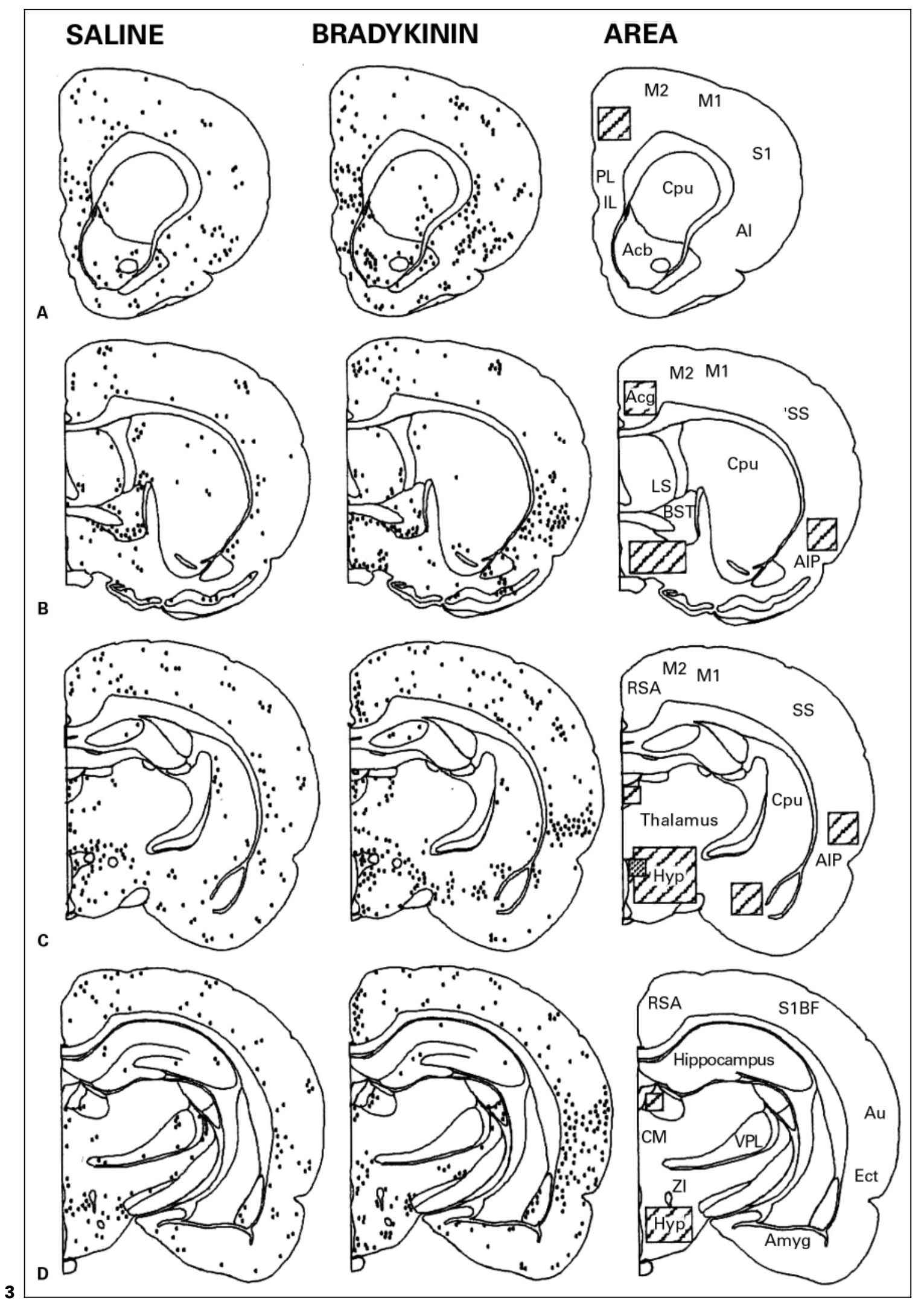

(For figure $3 \mathrm{E}-\mathrm{M}$ see next pages.) 


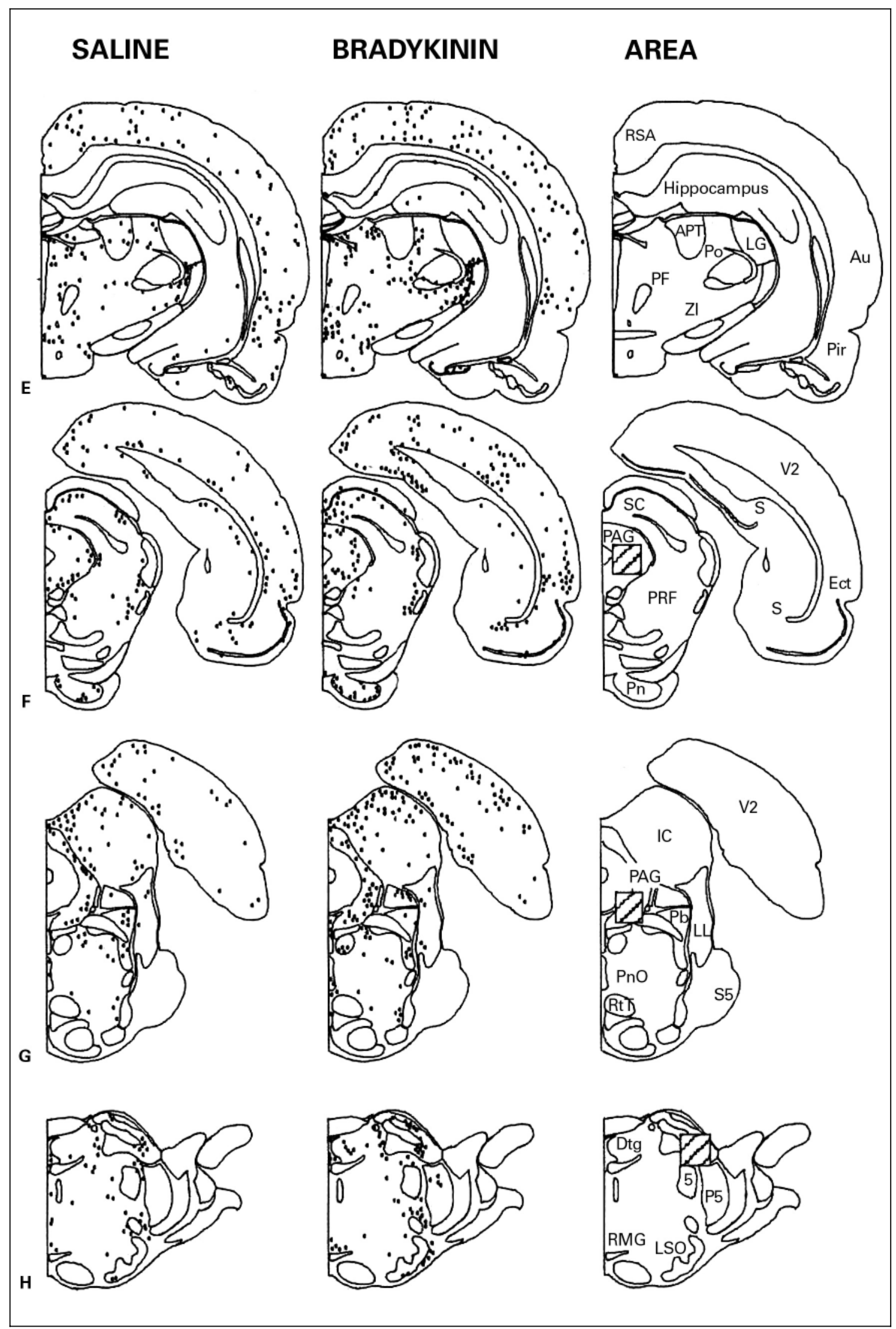




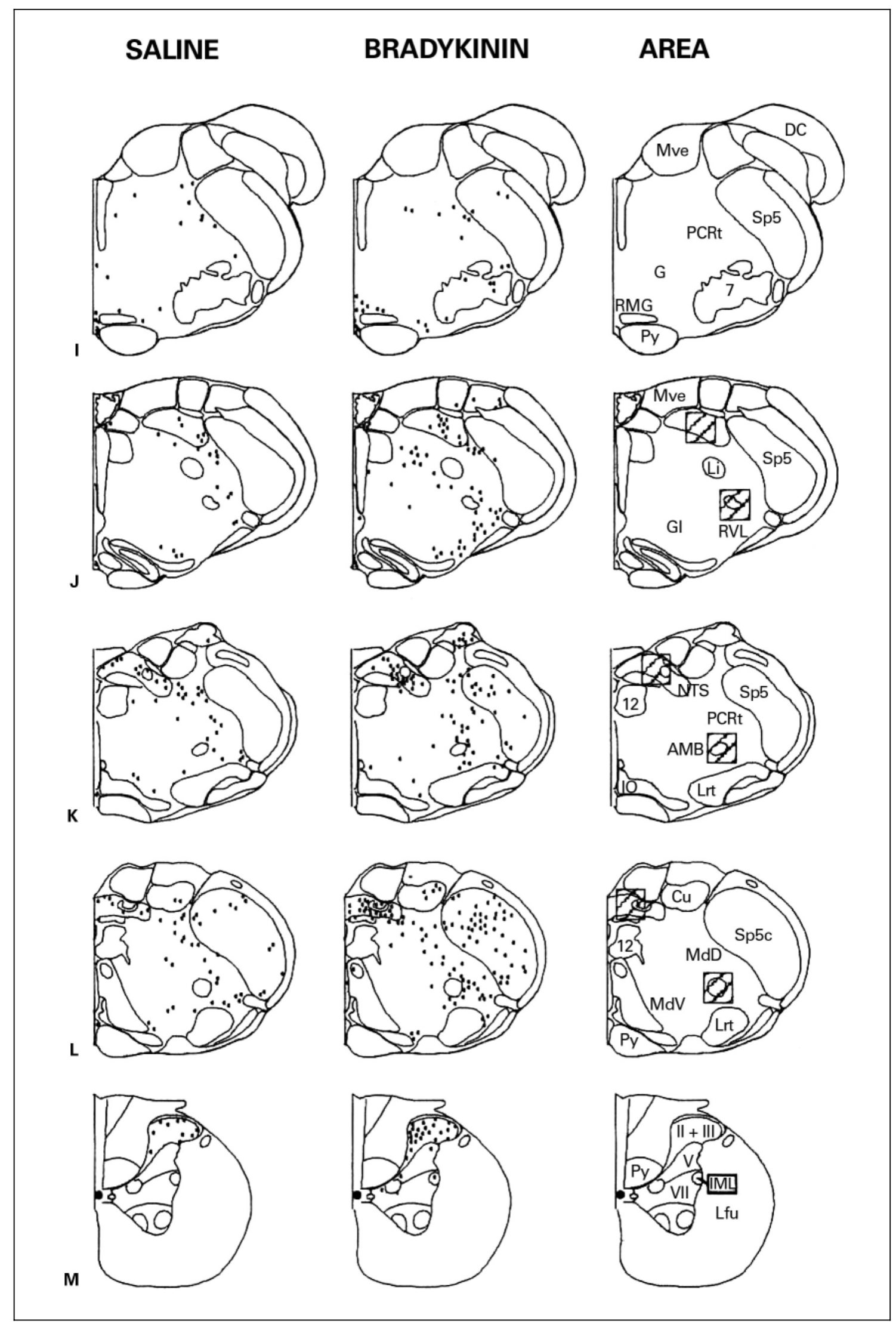



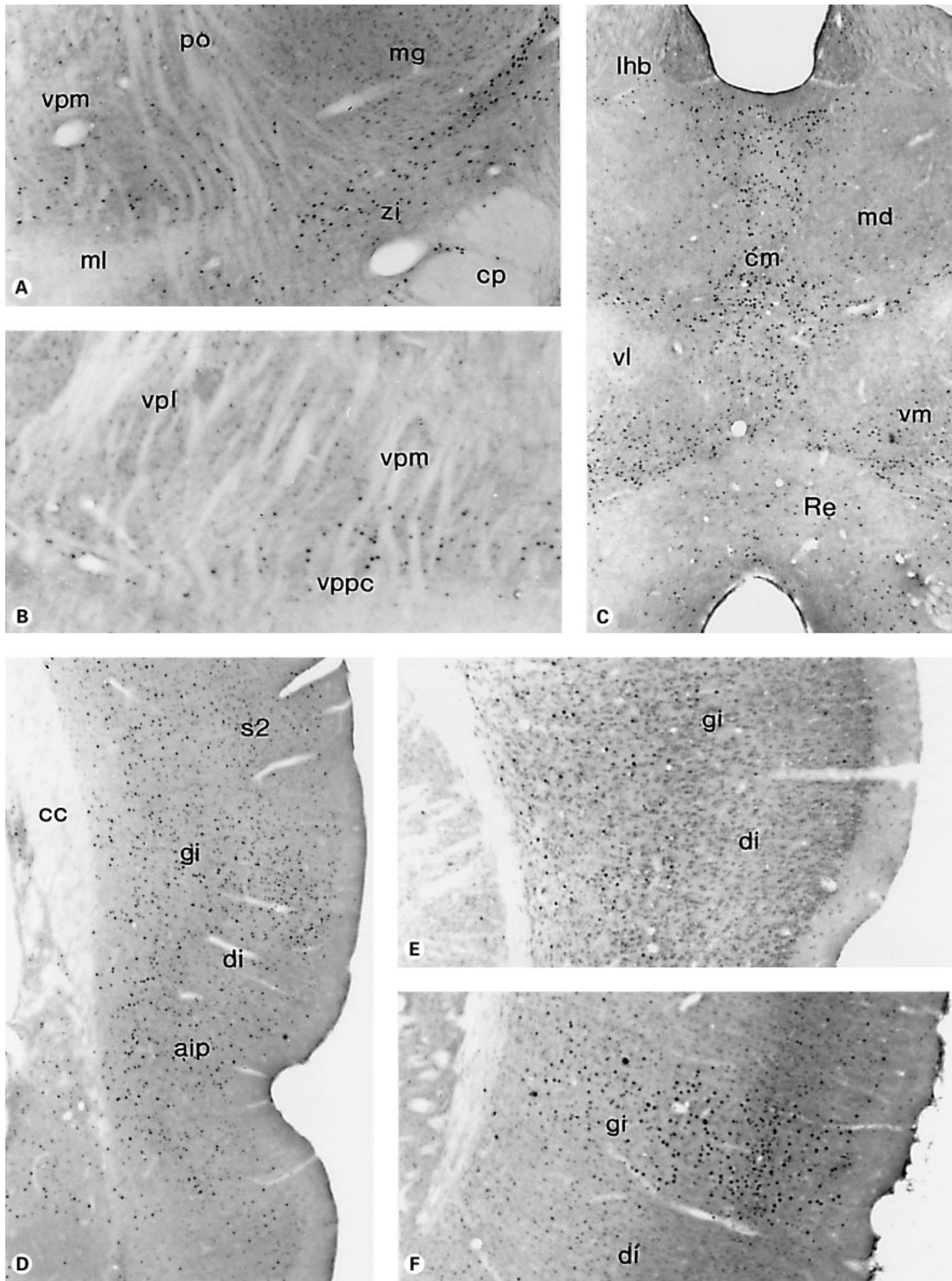

Fig. 4. Photomicrographs showing Fos expression in the caudal ventrolateral thalamus $(\mathbf{A}, \mathbf{B})$, the medial thalamus (C), and the insular cortex (D, E, F). A, B, F The pattern of Fos-ir after infusion of bradykinin in the pericardial sac. C, D Obtained from animals treated with capsaicin. E From a saline-treated animal. Note the selective labeling pattern in the granular insular field (F) after pericardial bradykinin infusion and the more generalized labeling in the same and adjoining cortical fields after capsaicin treatment (D). 

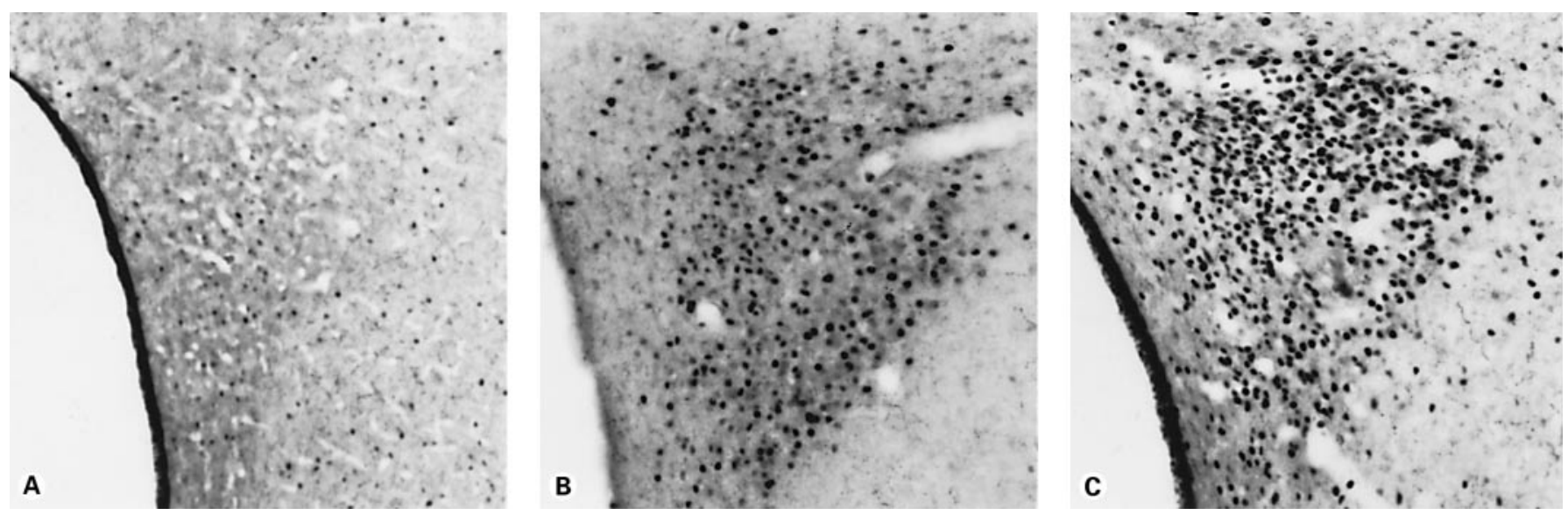

Fig. 5. Photomicrographs illustrating Fos-ir in the hypothalamic paraventricular nucleus after pericardial infusions of saline (A), bradykinin (B) and capsaicin (C).
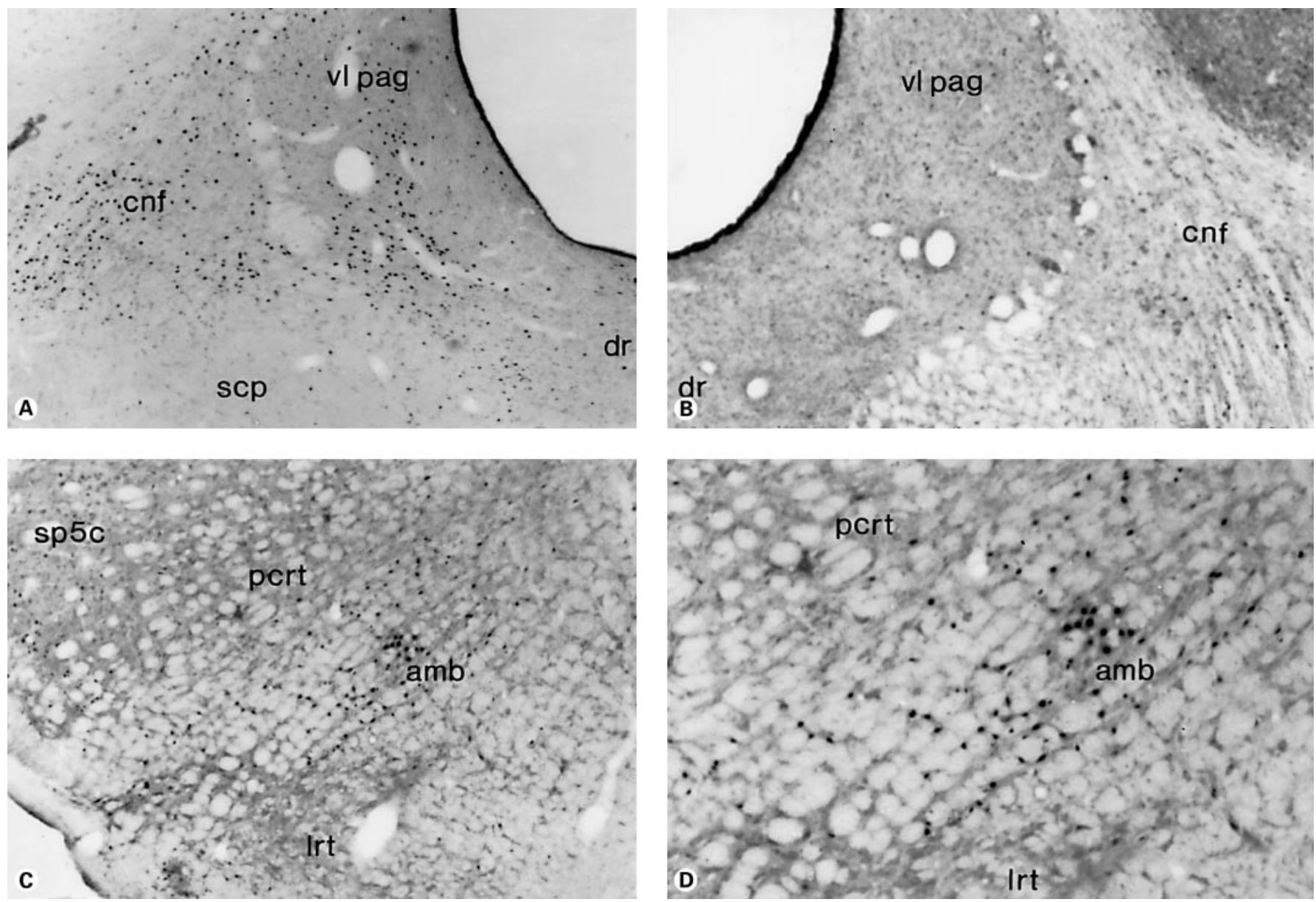

Fig. 6. Photomicrographs of Fos-ir in the ventrolateral PAG of bradykinin- (A) and saline-treated (B) animals. C Fos expression in the ventrolateral medulla oblongata in the (peri-)ambiguus area induced by pericardial application of bradykinin. D High-power magnification of $\mathbf{C}$. 

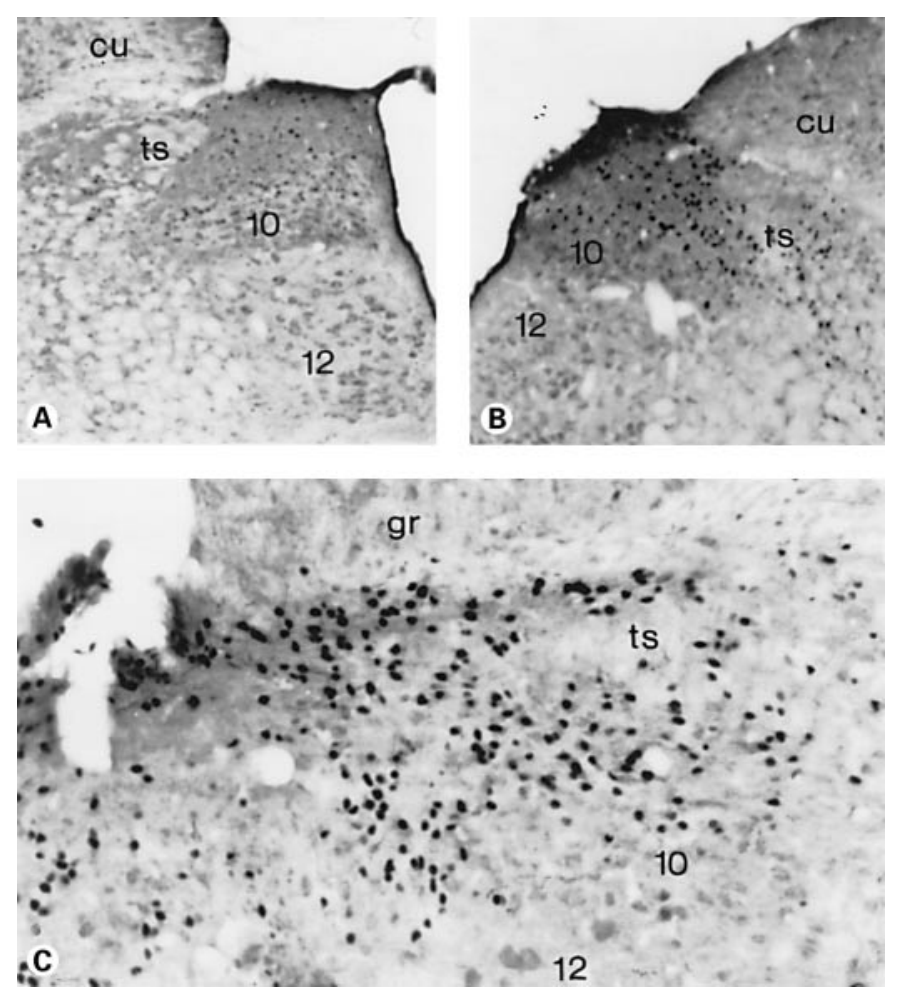

Fig. 7. Photomicrographs of the NTS illustrating the Fos expression in control (A), bradykinin- (B) and capsaicin-treated (C) animals. A, B Fos-ir at the intermediate NTS level. C High-power magnification of Fos-ir in the caudal visceral sensory part of the right NTS after infusion of capsaicin into the pericardial sac.

Bradykinin significantly increased Fos-ir in the central part of the nucleus of the solitary tract (NTS) (fig. 7B), the caudal parvocellular reticular formation, the raphe pallidus, the periambiguus nucleus (fig. $6 \mathrm{C}, \mathrm{D}$ ), and in the rostral and caudal ventrolateral reticular formation (fig. 3JL). In addition, the extern cuneate, the cuneate, the interpolar and caudal spinal trigeminal nuclei showed increased Fos-ir after bradykinin administration (fig. 3K, L). A few Fos-positive cells were located in the lateral dorsal motor vagus nucleus.

Fos expression in the spinal cord was increased in the dorsal laminae at the upper cervical levels and in the upper thoracic segments, particularly in the medial parts of laminae I-IV of the first 6 thoracic segments (fig. 3M). Most neurons expressing Fos-ir were situated in the medial parts of layers II and III of the thoracic cord (fig. 8B). The intermediolateral cell group and the dorsal spinal nucleus, located near the spinal canal, contained a few Fos-positive cells. Medial and lower thoracic segments showed small alterations of basal Fos expression after
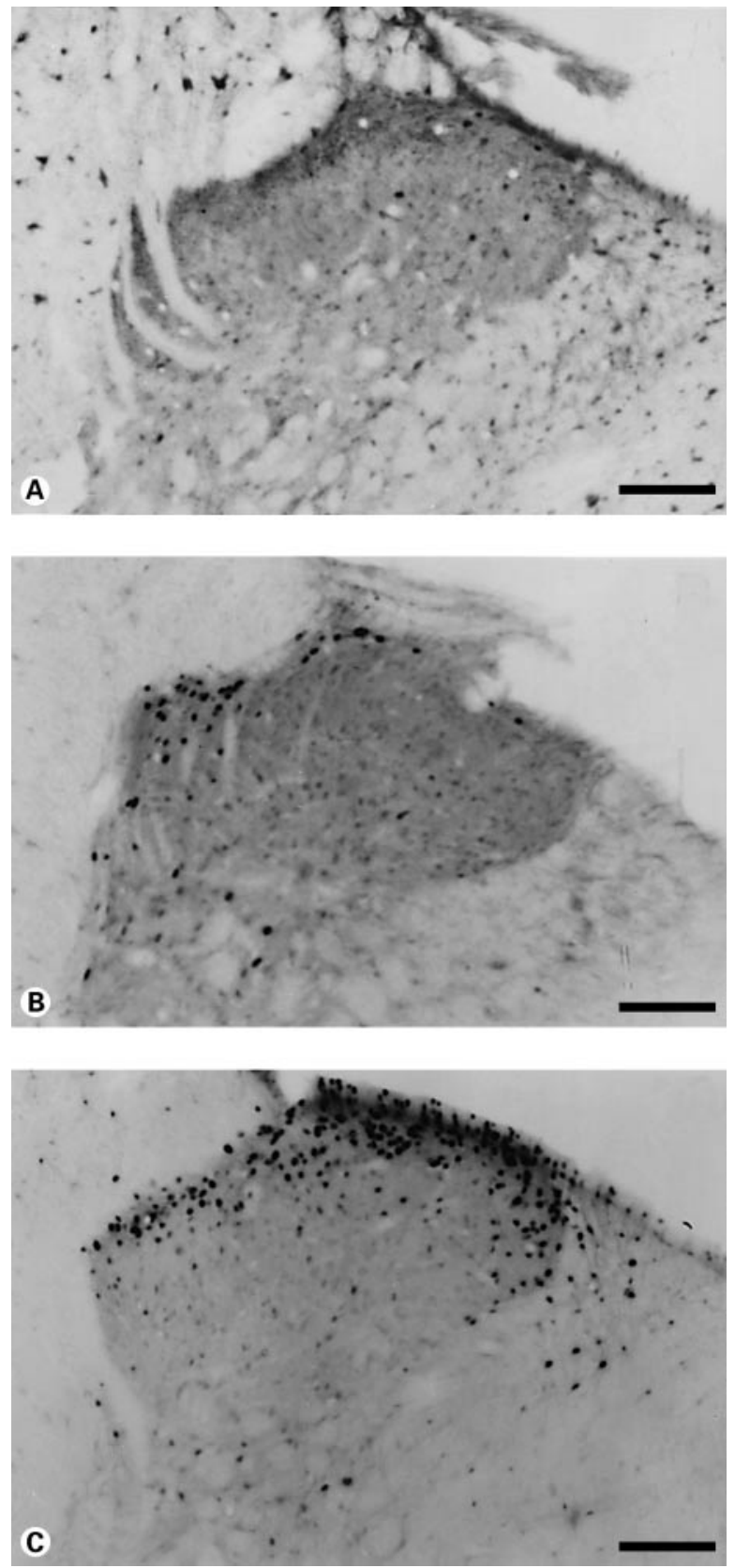

Fig. 8. Photomicrographs illustrating induction of Fos-ir in the thoracic spinal cord after infusions of saline (A) and bradykinin (B) into the pericardial sac. Note: capsaicin was not capable of inducing Fos-ir in the thoracic segments and produced control-like images as shown in A. C Fos-ir in thoracic segment 2 after infusion of a 3-fold increased volume of the capsaicin solution (150 instead of $50 \mu \mathrm{l})$. 
pericardial bradykinin administration. It was slightly increased in layers I-IV of the first lumbar levels.

\section{Fos Expression after Pericardial Capsaicin}

A more generalized increase in Fos expression was found after pericardial administration of capsaicin. The majority of regions showing Fos-ir following bradykinin infusions were also stained through capsaicin. The number of Fos-positive cells in the regions, however, was higher in many areas, including the NTS (fig. 7C), the LC, the subregions of the PAG, the paraventricular hypothalamic (fig. 5C) and thalamic nuclei, and the Acg (see quantification). Interestingly, large parts of the ventrolateral thalamic complex were Fos negative after administration of capsaicin, as has already been demonstrated in the bradykinin group. The SFPC, the VPLpc, the VPMpc, and the posterior thalamic nucleus, however, showed a moderately increased Fos labelling. Many cortical regions which were not or only slightly affected after pericardial bradykinin administration showed a significant Fos-ir expression after capsaicin infusions, in particular the somatosensory cortex. Fos-ir in the spinal trigeminal nucleus caudalis was reduced compared with the bradykinin-induced expression and both the cochlear nuclei and the inferior colliculi showed layers of Fos-expressing cells. The latter possibly is a consequence of increased sensitivity for selective acoustic signals associated with arousal. Increased sensitivity of the auditory system may also explain the increased regional Fos-ir pattern in the auditory cortical fields.

An important difference between capsaicin- and bradykinin-induced Fos-ir was apparent in the thoracic spinal cord. Capsaicin never induced increased Fos expression following pericardial administration, whereas there was a significant effect here following infusion of bradykinin (fig. 8A). To investigate whether this unresponsiveness results from the technique, the concentration of the capsaicin solution, or the lack of 'capsaicin receptors' on pericardial sensory afferents, capsaicin was administered subcutaneously on the chest at different dosages, thus stimulating sensory afferents that innervate the same dermatome. In these experiments, independent of the dosage, a significantly increased Fos expression was generated in the medial parts of layers I-IV of the upper thoracic segments, supporting previous studies [23] and providing evidence of capsaicin-unresponsive cardiac 'sympathetic' sensory afferents.

\section{Quantification of the Fos Expression}

In selective regions of the brain, previously associated with cardiovascular regulation and pain, the number of
Fos-ir cells was quantified (table 1). In the thoracic spinal cord, both the vehicle and capsaicin group showed a mean number of $7 \pm 1$ Fos-ir cells per hemisection. Bradykinin significantly increased the number of labelled cells to 15 $\pm 1(\mathrm{p}<0.001)$ in the upper thoracic segment. In the NTS, bradykinin significantly increased the Fos-ir at -13 and $-13.5 \mathrm{~mm}$ from bregma [vehicle: $14 \pm 4$ and $15 \pm 2$; bradykinin: $59 \pm 12(\mathrm{p}<0.05)$ and $53 \pm 7(\mathrm{p}<0.05)]$. Capsaicin-induced Fos-ir in the NTS was increased from -12.5 to $-14 \mathrm{~mm}$ [vehicle: $10 \pm 5,14 \pm 4,15 \pm 2,8 \pm 1$; capsaicin: $47 \pm 20(p<0.01), 144 \pm 3(p<0.001), 128 \pm$ $13(\mathrm{p}<0.001), 94 \pm 18(\mathrm{p}<0.01)]$. A drug-related effect was found at $-13 \mathrm{~mm}$ (capsaicin: $144 \pm 3$; bradykinin: 59 \pm 12 ).

The (peri-)ambiguus area showed a significantly increased Fos-ir between -12.5 and $-14 \mathrm{~mm}$ both in the bradykinin and capsaicin group [vehicle: $1 \pm 1,7 \pm 2,10$ $\pm 2,7 \pm 2$; bradykinin: $28 \pm 3(\mathrm{p}<0.001), 22 \pm 3(\mathrm{p}<$ $0.01), 30 \pm 4(\mathrm{p}<0.01), 24 \pm 3(\mathrm{p}<0.01)$; capsaicin: 18 $\pm 4(\mathrm{p}<0.01), 19 \pm 4(\mathrm{p}<0.05), 23 \pm 2(\mathrm{p}<0.01), 29 \pm$ $3(p<0.01)]$. The number of Fos-ir cells in the LC was not significantly affected by bradykinin administration, while it was significantly increased in the medial LC in the capsaicin group [vehicle: $11 \pm 3$; capsaicin: $62 \pm 16(\mathrm{p}<$ $0.05)]$. Moreover, these animals showed significantly more Fos-ir than the bradykinin-treated rats in the medial and caudal LC [bradykinin: $7 \pm 1,5 \pm 1$; capsaicin: $62 \pm$ $16(\mathrm{p}<0.01), 43 \pm 14(\mathrm{p}<0.05)]$. The rostral lateral parabrachial area showed a significantly increased Fos expression in the bradykinin group [vehicle: $25 \pm 2(\mathrm{p}<0.001)$ ], as well as effects of the drugs [bradykinin: $86 \pm 7$; capsaicin: $38 \pm 3(p<0.001)]$. Capsaicin and bradykinin significantly increased Fos-ir in the medial and caudal PAG [vehicle: $103 \pm 15,72 \pm 12,67 \pm 9$; capsaicin: $204 \pm 19$, $215 \pm 27(\mathrm{p}<0.001), 275 \pm 69(\mathrm{p}<0.001)$; bradykinin: $93 \pm 6,160 \pm 8(\mathrm{p}<0.01), 177 \pm 11(\mathrm{p}<0.01)]$, but all parts showed stronger responses in the capsaicin group [bradykinin: $93 \pm 6,160 \pm 8,177 \pm 11$; capsaicin: 204 $\pm 19(\mathrm{p}<0.001), 215 \pm 27(\mathrm{p}<0.05), 275 \pm 69(\mathrm{p}<$ $0.01)]$.

Bradykinin increased the Fos-ir in the rostral paraventricular thalamus nucleus [PVT; vehicle: $22 \pm 4$; bradykinin: $68 \pm 10(\mathrm{p}<0.01)]$ and capsaicin in the rostral and caudal PVT [vehicle: $22 \pm 4,17 \pm 2$; capsaicin: $49 \pm 9$ $(\mathrm{p}<0.01), 53 \pm 6(\mathrm{p}<0.001)]$. The increases in the caudal PVT [bradykinin: $38 \pm 3$; capsaicin: $53 \pm 6(\mathrm{p}<0.01)$ ] and the rostral PVN [vehicle: $37 \pm 10$; bradykinin: $38 \pm$ 3; capsaicin: $168 \pm 14(\mathrm{p}<0.001)]$ were significantly higher in the capsaicin group. In the caudal PVN, both groups showed a significantly increased Fos-ir [vehicle: 39 
Table 1. Quantification of Fos-ir in selective regions of the rat brain after saline, bradykinin, and capsaicin infusion into the pericardial sac of conscious animals

\begin{tabular}{|c|c|c|c|}
\hline Area & Control & Bradykinin & Capsaicin \\
\hline \multicolumn{4}{|c|}{ Brainstem and thoracic spinal cord } \\
\hline Th2/Th3 & $7 \pm 1$ & $15 \pm 1^{\mathrm{a}}$ & $7 \pm 1^{\mathrm{b}}$ \\
\hline \multicolumn{4}{|l|}{ NTS } \\
\hline-12.5 & $10 \pm 5$ & $32 \pm 7$ & $47 \pm 20^{a}$ \\
\hline-13 & $14 \pm 4$ & $59 \pm 12^{\mathrm{a}}$ & $144 \pm 3^{\mathrm{a}, \mathrm{b}}$ \\
\hline-13.5 & $15 \pm 2$ & $53 \pm 7^{a}$ & $128 \pm 13^{\mathrm{a}}$ \\
\hline-14 & $8 \pm 1$ & $34 \pm 15$ & $94 \pm 18^{\mathrm{a}}$ \\
\hline-14.5 & $9 \pm 2$ & $31 \pm 9$ & $47 \pm 2$ \\
\hline \multicolumn{4}{|c|}{ (Peri-)ambiguus } \\
\hline-12.5 & $1 \pm 1$ & $28 \pm 3^{\mathrm{a}}$ & $18 \pm 4^{\mathrm{a}}$ \\
\hline-13 & $7 \pm 2$ & $22 \pm 3^{\mathrm{a}}$ & $19 \pm 4^{\mathrm{a}}$ \\
\hline-13.5 & $10 \pm 2$ & $30 \pm 4^{\mathrm{a}}$ & $23 \pm 2^{\mathrm{a}}$ \\
\hline-14 & $7 \pm 2$ & $24 \pm 3^{\mathrm{a}}$ & $29 \pm 3^{\mathrm{a}}$ \\
\hline-14.5 & $8 \pm 4$ & $9 \pm 1$ & $12 \pm 3$ \\
\hline \multicolumn{4}{|l|}{ Midbrain } \\
\hline \multicolumn{4}{|l|}{$\mathrm{LC}$} \\
\hline Rostral & $17 \pm 4$ & $6 \pm 1$ & $33 \pm 14$ \\
\hline Medial & $11 \pm 3$ & $7 \pm 1$ & $62 \pm 16^{\mathrm{a}, \mathrm{b}}$ \\
\hline Caudal & $8 \pm 3$ & $5 \pm 1$ & $43 \pm 14^{b}$ \\
\hline \multicolumn{4}{|c|}{ Lateral parabrachial nucleus } \\
\hline Rostral & $25 \pm 2$ & $86 \pm 7^{\mathrm{a}}$ & $38 \pm 3^{b}$ \\
\hline Caudal & $10 \pm 2$ & $12 \pm 2$ & $28 \pm 9$ \\
\hline \multicolumn{4}{|l|}{ PAG } \\
\hline Rostral & $103 \pm 15$ & $93 \pm 6$ & $204 \pm 19 \mathrm{~b}$ \\
\hline Medial & $72 \pm 12$ & $160 \pm 8^{a}$ & $215 \pm 27 \mathrm{a}, \mathrm{b}$ \\
\hline Caudal & $67 \pm 9$ & $177 \pm 11^{\mathrm{a}}$ & $275 \pm 69^{a, b}$ \\
\hline \multicolumn{4}{|c|}{ Hypothalamus and thalamus } \\
\hline \multicolumn{4}{|c|}{ PVT } \\
\hline Rostral & $22 \pm 4$ & $68 \pm 10^{\mathrm{a}}$ & $49 \pm 9$ \\
\hline Caudal & $17 \pm 2$ & $38 \pm 2$ & $53 \pm 6^{\mathrm{a}, \mathrm{b}}$ \\
\hline \multicolumn{4}{|c|}{ Hypothalamus } \\
\hline Rostral & $95 \pm 10$ & $225 \pm 19^{a}$ & $202 \pm 18^{a}$ \\
\hline Medial & $83 \pm 3$ & $212 \pm 21^{\mathrm{a}}$ & $184 \pm 13^{\mathrm{a}}$ \\
\hline Caudal & $67 \pm 10$ & $91 \pm 18$ & $142 \pm 22^{\mathrm{a}}$ \\
\hline \multicolumn{4}{|l|}{ PVN } \\
\hline Rostral & $37 \pm 10$ & $38 \pm 3$ & $168 \pm 14^{\mathrm{a}, \mathrm{b}}$ \\
\hline Caudal & $39 \pm 5$ & $85 \pm 4^{\mathrm{a}}$ & $88 \pm 10^{\mathrm{a}}$ \\
\hline \multicolumn{4}{|l|}{ Forebrain } \\
\hline \multicolumn{4}{|c|}{ Central amygdala } \\
\hline Rostral & $6 \pm 1$ & $20 \pm 5$ & $17 \pm 5$ \\
\hline Medial & $14 \pm 5$ & $43 \pm 4^{\mathrm{a}}$ & $38 \pm 4^{\mathrm{a}}$ \\
\hline Caudal & $10 \pm 2$ & $46 \pm 9^{a}$ & $40 \pm 5^{\mathrm{a}}$ \\
\hline \multicolumn{4}{|c|}{ Insular cortex } \\
\hline Rostral & $18 \pm 3$ & $95 \pm 18^{a}$ & $39 \pm 5$ \\
\hline Caudal & $22 \pm 3$ & $80 \pm 15^{\mathrm{a}}$ & $51 \pm 6^{\mathrm{a}}$ \\
\hline \multicolumn{4}{|l|}{ Acg } \\
\hline Rostral & $21 \pm 4$ & $37 \pm 6$ & $55 \pm 9^{a}$ \\
\hline Medial & $13 \pm 3$ & $23 \pm 3^{b}$ & $63 \pm 12^{a}$ \\
\hline Caudal & $6 \pm 2$ & $18 \pm 6^{\mathrm{b}}$ & $49 \pm 5^{\mathrm{a}}$ \\
\hline
\end{tabular}

Significant effects compared with the control $\left({ }^{\mathrm{a}} \mathrm{p}<0.05\right)$ and bradykinin-induced expression levels $\left({ }^{b} \mathrm{p}<0.05\right)$ are indicated. \pm 5; bradykinin: $85 \pm 4(\mathrm{p}<0.05)$; capsaicin: $88 \pm 10$ $(\mathrm{p}<0.05)]$. A gradually decreasing Fos expression was found in the hypothalamus from rostral to caudal [vehicle: $95 \pm 10,83 \pm 3,67 \pm 10$; bradykinin: $225 \pm 19(\mathrm{p}<$ $0.001), 212 \pm 21(\mathrm{p}<0.001), 91 \pm 18$; capsaicin: $202 \pm$ $18(\mathrm{p}<0.001), 184 \pm 13(\mathrm{p}<0.01), 142 \pm 22(\mathrm{p}<0.05)]$. In both treatment groups the medial and caudal parts of the central amygdala were activated [vehicle: $14 \pm 5,10$ \pm 2 ; bradykinin: $43 \pm 4(\mathrm{p}<0.01), 46 \pm 9(\mathrm{p}<0.05)$; capsaicin: $38 \pm 4(\mathrm{p}<0.05), 40 \pm 5(\mathrm{p}<0.05)]$. Bradykinin nonsignificantly increased Fos-ir in the Acg (vehicle: $21 \pm 4,13 \pm 3,6 \pm 2$; bradykinin: $37 \pm 6,23 \pm 12,18$ $\pm 6)$; the effect was more significant in the capsaicin group [55 $\pm 9(\mathrm{p}<0.05), 63 \pm 12(\mathrm{p}<0.01), 49 \pm 5(\mathrm{p}<$ $0.001)]$. Group differences were found in the medial and caudal Acg [bradykinin: $63 \pm 12(\mathrm{p}<0.05), 49 \pm 5(\mathrm{p}<$ $0.05)$; capsaicin: $23 \pm 3,18 \pm 6)]$. Bradykinin triggered a selective Fos expression in the insular cortex [visceral fields according to Swanson [62]; fig. 4F; vehicle: $18 \pm 3$, $22 \pm 3$; bradykinin: $95 \pm 18(\mathrm{p}<0.001), 80 \pm 15(\mathrm{p}<$ $0.01)]$; capsaicin triggered Fos expression only in the caudal part of the insular cortex [vehicle: $22 \pm 3$; capsaicin: $51 \pm 6(\mathrm{p}<0.05)]$.

\section{Discussion}

The onset of angina pectoris, usually the result of ischemic episodes in the myocardium, is initiated through excitation of chemosensitive and mechanoreceptive receptors in the heart. During these ischemic episodes, a collage of chemicals is released that excites the receptors of the sympathetic and vagal afferent pathways. Afferent fibers from the heart and coronary arteries respond vigorously to pain-inducing chemicals when applied to the epicardial surface or injected directly into coronary arteries $[3,24,25]$. In our study, cardiac pain was produced by algesic inflammatory substances, i.e. bradykinin or capsaicin infusions into the pericardial sac. In general, areas that showed an increase in Fos expression following the induction of cardiac pain are considered to be involved in the perception or integration of cardiac pain. A potential initiator of Fos-ir is the cardiovascular emergency response. The Fos expression was significantly increased in the cardiovascular control areas [26-32], including the NTS, the periambiguus area, the ventrolateral reticular formation, and the parabrachial complex, the ventrolateral PAG, the hypothalamus, and the central amygdala. In our study, bradykinin and capsaicin showed different changes in cardiovascular response (fig. 2); while bradyki- 
nin administration was followed by an immediate but nonsignificant rise in heart rate (heart rate was elevated for $1 \mathrm{~h}$ and then followed by a slight decrease) (fig. 2A), capsaicin caused only a slight decrease in heart rate during the first $20 \mathrm{~min}$ (fig. 2C). These slight changes in the heart rate of rats cannot induce a significant increase in Fos expression in these cardiovascular control areas of the brain. Furthermore, bradykinin did not generate significant changes in mean arterial pressure, while capsaicin generated biphasic hypertension. Hypertension has been found to induce Fos expression in the medial NTS, the baroreceptor strip of the commissural NTS, and the caudal ventrolateral medulla [33]. However, hypertension and noxious myocardial stimulation-induced Fos expressions in the brainstem are not compatible. Therefore, changes in cardiovascular responses cannot be responsible for a significant increase in Fos expression in our study.

In order to further increase the significance of the results, only those areas which showed a significant increase in Fos expression following both bradykinin and capsaicin administration were considered to be of importance in the perception and integration of cardiac nociception. Table 2 summarizes the areas that showed Fos expression in conscious rats after pericardial noxious stimulation with bradykinin and capsaicin. Column 3 of table 2 lists the areas that showed moderate and strong increases in Fos expression in both groups.

\section{Spinal Cord}

Fos expression in the spinal cord was increased in the dorsal laminae at the upper cervical levels and in the upper thoracic segments. Sympathetic afferent fibers from the heart enter the upper thoracic spinal cord and synapse on the cells of origin of the ascending pathways. These fibers generally have their cell bodies in the dorsal root ganglia of the $\mathrm{C}_{8}-\mathrm{T}_{9}$ spinal segments $[34,35]$. These dorsal root ganglion cells have axons entering the tract of Lissauer and terminating in the same segment or ascending and descending a few segments before they penetrate into the spinal cord [36].

The upper cervical segment is an important area, which is thought to provide a neural substrate for referred pain originating from the heart. In our study, the upper cervical segment also showed increased Fos expression in the dorsal laminae. Somatic receptive fields for $\mathrm{C}_{1}-\mathrm{C}_{3}$ neurons are found most commonly in the areas of the neck, jaw, ear, and upper arm. These neurons are far removed from the entry zone of the cardiac afferent fibers, which is primarily in the $T_{2}-T_{6}$ dorsal root ganglia
Table 2. Semiquantitative description of the Fos expression in the rat brain after noxious myocardial stimulation with bradykinin and capsaicin

\begin{tabular}{|c|c|c|c|}
\hline List of structures & $\begin{array}{l}\text { Brady- } \\
\text { kinin }\end{array}$ & $\begin{array}{l}\text { Cap- } \\
\text { saicin }\end{array}$ & $\begin{array}{l}\text { Acti- } \\
\text { vated }\end{array}$ \\
\hline \multicolumn{4}{|l|}{ Cortex } \\
\hline Agranular insular cortex & ++ & + & \\
\hline Cingulate cortex & ++ & +++ & $\mathrm{y}$ \\
\hline Dysgranular insular cortex & + & + & \\
\hline Ectorhinal cortex & - & + & \\
\hline Entorhinal cortex & + & + & \\
\hline Frontal association cortex & + & + & \\
\hline Granular insular cortex & ++ & ++ & $\mathrm{y}$ \\
\hline Infralimbic cortex & ++ & +++ & $\mathrm{y}$ \\
\hline Parietal association cortex & + & ++ & \\
\hline Perirhinal cortex & - & ++ & \\
\hline Piriform cortex & - & ++ & \\
\hline Prelimbic cortex & ++ & +++ & $\mathrm{y}$ \\
\hline Primary auditory cortex & ++ & +++ & $\mathrm{y}$ \\
\hline Primary motor cortex & + & ++ & \\
\hline Primary somatosensory cortex & ++ & +++ & $\mathrm{y}$ \\
\hline Primary visual cortex & ++ & +++ & $\mathrm{y}$ \\
\hline Retrosplenial agranular cortex & ++ & +++ & $\mathrm{y}$ \\
\hline Retrosplenical granular cortex & ++ & +++ & $\mathrm{y}$ \\
\hline Secondary auditory cortex & ++ & +++ & $\mathrm{y}$ \\
\hline Secondary motor cortex & + & ++ & \\
\hline Secondary somatosensory cortex & ++ & ++ & $\mathrm{y}$ \\
\hline Secondary visual cortex & + & ++ & \\
\hline Temporal association cortex & ++ & +++ & $\mathrm{y}$ \\
\hline \multicolumn{4}{|l|}{ Other forebrain } \\
\hline Accumbens nucleus, core & + & - & \\
\hline Accumbens nucleus, shell & + & ++ & \\
\hline Caudate putamen (striatum) & - & + & \\
\hline Lateral globus pallidus & - & - & \\
\hline Lateral septal nucleus & ++ & + & \\
\hline Medial globus pallidus & + & - & \\
\hline Medial septal nucleus & - & - & \\
\hline Nucleus horizontal limb diagonal band & - & - & \\
\hline Nucleus vertical limb diagonal band & + & ++ & \\
\hline Subiculum & + & ++ & \\
\hline
\end{tabular}

\section{Amygdala}

Amygdalohippocampal area

Anterior cortical amygdaloid nucleus

Basolateral amygdaloid nucleus

Basomedial amygdaloid nucleus

Central amygdaloid nucleus

Lateral amygdaloid nucleus

Medial amygdaloid nucleus

Midbrain

Anterior pretectal nucleus

Dorsolateral periaqueductal gray

Cuneiform nucleus

Deep gray layer of ther superior colliculus

Dorsal raphe nucleus

Dorsomedial periaqueductal gray

Intermediate gray layer of the superior colliculus

Interpeduncular nucleus

Lateral peraqueductal gray

Medial pretectal nucleus

Median raphe nucleus

Peripeduncular nucleus

Posterior pretectal nucleus

Red nucleus

$\begin{array}{lll}+ & + & \\ - & + & \\ + & ++ & \\ + & ++ & \\ ++ & ++ & y \\ - & - & \\ ++ & +++ & y\end{array}$

$\begin{array}{lll}+ & + & \\ ++ & ++ & y \\ ++ & ++ & y \\ + & ++ & \\ ++ & ++ & y \\ + & + & \\ ++ & ++ & y \\ + & + & \\ + & + & \\ - & - & \\ + & + & \\ ++ & + & \\ - & - & \\ - & -\end{array}$


Table 2 (continued)

\begin{tabular}{|c|c|c|c|}
\hline List of structures & $\begin{array}{l}\text { Brady- } \\
\text { kinin }\end{array}$ & $\begin{array}{l}\text { Cap- } \\
\text { saicin }\end{array}$ & $\begin{array}{l}\text { Acti- } \\
\text { vated }\end{array}$ \\
\hline \multicolumn{4}{|l|}{ Midbrain (continued) } \\
\hline Substantia nigra & - & + & \\
\hline Ventral tegmental area & ++ & + & \\
\hline Ventral tegmental nucleus & ++ & - & \\
\hline Ventrolateral periaqueductal gray & +++ & +++ & $\mathrm{y}$ \\
\hline \multicolumn{4}{|l|}{ Pons } \\
\hline Deep meseancephalic nucleus & + & ++ & \\
\hline Cortex inferior colliculus & ++ & ++ & $\mathrm{y}$ \\
\hline Dorsal tegmental nucleus & ++ & - & \\
\hline Dorsomedial tegmental area & + & ++ & \\
\hline Kölliker-Fuse nucleus & ++ & ++ & $\mathrm{y}$ \\
\hline Lateral parabrachial nucleus & ++ & ++ & $\mathrm{y}$ \\
\hline Lateral vestibular nucleus & - & - & \\
\hline Laterodorsal tegmental nucleus & ++ & ++ & $\mathrm{y}$ \\
\hline Locus coeruleus & - & ++ & \\
\hline Medial parabrachial nucleus & + & + & \\
\hline Medial vestibular nucleus & - & - & \\
\hline Pedunculopontine tegmental nucleus & ++ & ++ & $\mathrm{y}$ \\
\hline Pontine nuclei & ++ & +++ & $\mathrm{y}$ \\
\hline Pontine raphe nucleus & + & + & \\
\hline Pontine reticular nucleus & + & + & \\
\hline Spinal vestibular nucleus & - & - & \\
\hline Subcoeruleus nucleus & - & + & \\
\hline Superior vestibular nucleus & - & - & \\
\hline Ventral cochlear nucleus & ++ & ++ & $\mathrm{y}$ \\
\hline \multicolumn{4}{|l|}{ Thalamus } \\
\hline Anterodorsal thalamic nucleus & - & + & \\
\hline Anteromedial thalamic nucleus & - & ++ & \\
\hline Anteroventral thalamic nucleus & - & + & \\
\hline Central medial thalamic nucleus & ++ & +++ & $\mathrm{y}$ \\
\hline Centrolateral thalamic nucleus & ++ & +++ & $\mathrm{y}$ \\
\hline Intergeniculate leaf & +++ & +++ & $\mathrm{y}$ \\
\hline Dorsal lateral geniculate nucleus & - & + & \\
\hline Lateral habenular nucleus & + & ++ & \\
\hline Lateral posterior thalamic nucleus & + & + & \\
\hline Laterodorsal thalamic nucleus & - & - & \\
\hline Medial geniculate nucleus & + & + & \\
\hline Medial habenular nucleus & - & - & \\
\hline Mediodorsal thalamic nucleus & + & ++ & \\
\hline Olivary pretectal nucleus & + & + & \\
\hline Paracentral thalamic nucleus & - & ++ & \\
\hline Parafascicular thalamic nucleus & - & - & \\
\hline Paraventricular thalamic nucleus & +++ & +++ & $\mathrm{y}$ \\
\hline Posterior intralaminar thalamic nucleus & ++ & ++ & $\mathrm{y}$ \\
\hline Posterior thalamic nuclear group & + & + & \\
\hline Posteromedian thalamic nucleus & - & - & \\
\hline Reticular thalamic nucleus & - & - & \\
\hline Reuniens thalamic nucleus & - & ++ & \\
\hline Rhomboid thalamic nucleus & ++ & ++ & $\mathrm{y}$ \\
\hline Submammillothalamic nucleus & - & - & \\
\hline Submedius thalamic nucleus & - & - & \\
\hline Subparafascicular thalamic nucleus & ++ & ++ & $\mathrm{y}$ \\
\hline Subthalamic nucleus & - & - & \\
\hline Ventral anterior thalamic nucleus & - & + & \\
\hline Ventral lateral geniculate nucleus & + & + & \\
\hline Ventral posterior thalamic nucleus & - & - & \\
\hline Ventral posterolateral thalamic nucleus & ++ & ++ & $\mathrm{y}$ \\
\hline Ventral posteromedial thalamic nucleus & ++ & ++ & $\mathrm{y}$ \\
\hline Ventrolateral thalamic nucleus & - & - & \\
\hline Ventromedial thalamic nucleus & - & + & \\
\hline
\end{tabular}

\begin{tabular}{llll}
\hline List of structures & $\begin{array}{l}\text { Brady- } \\
\text { kinin }\end{array}$ & $\begin{array}{l}\text { Cap- } \\
\text { saicin }\end{array}$ & $\begin{array}{l}\text { Acti- } \\
\text { vated }\end{array}$ \\
\hline
\end{tabular}

\section{Hypothalamus}

Anterior hypothalamic area

Bed nucleus of the stria terminalis

Arcuate hypothalamic nucleus

Dorsal hypothalamic area

Dorsomedial hypothalamic nucleus

Lateral hypothalamic area

Lateral mammillary nucleus

Lateral preoptic area

Lateroanterior hypothalamic nucleus

Medial mammillary nucleus

Medial preoptic nucleus

Median preoptic nucleus

Paraventricular hypothalamic nucleus

Perifornical nucleus

Posterior hypothalamic area

Premammillary nucleus, dorsal part

Premammillary nucleus, ventral part

Retrochiasmatic area

Suprachiasmatic nucleus

Supramammillary nucleus

Supraoptic nucleus

Ventromedial hypothalamic nucleus

Zona incerta

$\begin{array}{llll}+ & + & \\ ++ & ++ & \mathrm{y} \\ + & + & \\ ++ & ++ & \mathrm{y} \\ ++ & ++ & \mathrm{y} \\ ++ & ++ & \mathrm{y} \\ + & + & \\ + & ++ & \\ + & - & \\ + & - & \\ + & + & \\ ++ & + & \\ ++ & ++ & \mathrm{y} \\ ++ & ++ & \mathrm{y} \\ + & + & \\ + & + & \\ - & - & \\ +++ & ++ & \mathrm{y} \\ ++ & + & \\ + & + & \\ ++ & ++ & \mathrm{y} \\ + & ++ & \\ ++ & ++ & \mathrm{y} \\ + & & \end{array}$

Medulla oblongata

(Peri)ambiguus nucleus

Cuneate nucleus

Area postrema

Caudoventrolateral reticular nucleus

Dorsal motor nucleus of vagus

Dorsal paragigantocellular nucleus

External cuneate nucleus

Gigantocellular reticular nucleus

Gracile nucleus

Hypoglossal nucleus

Inferior olive

Intermediate reticular nucleus

Lateral paragigantocellular nucleus

Lateral reticular nucleus

Lateral superior olive

Medial superior olive

Medullary reticular nucleus, dorsal part

Medullary reticular nucleus, ventral part

Motor trigeminal nucleus

Nucleus of the solitary tract

Nucleus of the trapezoid body

Parvicellular reticular nucleus

Prepositus nucleus

Principal sensory trigeminal nucleus

Raphe magnus nucleus

Raphe obscurus nucleus

Raphe pallidus nucleus

Rostroventrolateral reticular nucleus

Spinal trigeminal nucleus, caudal part

Spinal trigeminal nucleus, interpolar part

Spinal trigeminal nucleus, oral part

\begin{tabular}{|c|c|c|}
\hline++ & ++ & $\mathrm{y}$ \\
\hline- & - & \\
\hline- & + & \\
\hline++ & ++ & $\mathrm{y}$ \\
\hline+ & + & \\
\hline- & - & \\
\hline+ & - & \\
\hline- & - & \\
\hline- & - & \\
\hline- & - & \\
\hline- & - & \\
\hline++ & - & \\
\hline+ & + & \\
\hline+ & ++ & \\
\hline- & - & \\
\hline++ & + & \\
\hline++ & ++ & $\mathrm{y}$ \\
\hline- & - & \\
\hline - & - & \\
\hline+++ & +++ & $\mathrm{y}$ \\
\hline- & - & \\
\hline++ & + & \\
\hline+ & + & \\
\hline+ & - & \\
\hline++ & ++ & $\mathrm{y}$ \\
\hline+ & + & \\
\hline++ & ++ & $\mathrm{y}$ \\
\hline+ & + & \\
\hline+++ & + & \\
\hline+ & + & \\
\hline- & - & \\
\hline
\end{tabular}

The symbols indicate small, moderate, and significant increases of the Fos expression in the treated groups compared with the saline control group. Regions responding with moderate and/or strong increases in Fos expression in both treated groups are marked with a ' $y$ ' in the last column. $-=$ Lack of Fos expression; $+=$ small, $++=$ moderate $;+++=$ strong increases. 
$[34,37]$. It is most likely that cardiac afferent input enters the thoracic spinal cord and ascends in the ventrolateral quadrant of the spinal cord before it synapses on the upper cervical segment neurons [38]. This suggestion is based on information that excitation of neurons in the upper thoracic spinal segment by splanchnic nerve stimulation is abolished when the ventolateral part of the cord is cut rostral to the $\mathrm{T}_{7}$ segment [38]. The splanchnic nerve has its primary point of entry in the $T_{9}-\mathrm{T}_{11}$ segment of the spinal cord. This confirms the suggestion that the pool of neurons in the upper cervical segment of the spinal cord provides a neural substrate for referred pain originating from the heart and perceived in the neck and jaw region [3].

In contrast to bradykinin (fig. 8C), capsaicin never induced increased Fos expression in the spinal cord following pericardial administration, while there was significant increase in Fos expression in the upper thoracic spinal cord segment when capsaicin was administrated subcutaneously to the chest. Since the upper thoracic segment is the site of entrance of the cardiac sympathetic fibers, the lack of c-fos expression when capsaicin was used indicates that pericardial infusion with capsaicin did not activate cardiac sympathetic fibers. This finding provides evidence for capsaicin unresponsiveness to 'sympathetic' sensory afferents [23]. Whereas bradykinin activated the sympathetic fibers, capsaicin most probably used the afferents of the vagus nerve to induce the behavioral effects of the rats. Pericardial infusion of both capsaicin and bradykinin led to an increase in Fos expression in the NTS. The NTS is the site of termination of the cardiac vagal afferents, which can be activated following both vagal or sympathetic stimulation. Since capsaicin cannot activate cardiac sympathetic afferents, vagal activation is the most acceptable explanation for the increase in Fos expression in the NTS following pericardial capsaicin administration.

\section{Thalamus}

Visceral information from the spinal segments usually converges with input from somatic structures and ascends to the medial and lateral thalamus [39]. Somatic pain is mediated through the ventrobasal thalamus and selective parts of this cell group are implicated in visceral pain transmission [40, 41]. After pericardial noxious stimulation in conscious rats, a significant increase in the Foslabeled cells was found in the VPLpc, the VPMpc, the SFPC, and the medial nuclei of the thalamus (fig. 4A, B).

The VPLpc and the VPMpc both project to the posterior, granular and agranular insular cortex [42], which has- been recognized as the visceral sensory cortex [43]. Compared with the significantly increased Fos expression in the insular cortex, the number of Fos-positive cells in the ventroposterior thalamus was small. Limited thalamic Fos expression was also found in anesthetized animals after visceral or superficial noxious stimulation [18]. This suggests that alternative pathways may mediate visceral pain signals to the cerebral cortex.

Based on our observations, we suggest SFPC as an alternative thalamic region for the transmission of visceral pain to the cerebral cortex. Efferents originating from the SFPC innervate the limbic forebrain [44], the PAG [45], and the spinal cord [44]. This wide pattern of innervation does not support a selective role for the SFPC in thalamocortical pain transmission. Most likely, SFPC plays a crucial role in circuitry for emotional coping responses and/or pain.

The midline dorsal thalamic nuclei were also affected by noxious myocardial stimulation and accordingly they can relay the signal to the visceral sensory cortex. The paraventricular, the centrolateral, the centromedial, and the rhomboid midline thalamic nuclei, all showing increased Fos expression after noxious myocardial stimulation, maintain reciprocal connections with the cortical and subcortical limbic nuclei, including the amygdala, the hippocampus, the hypothalamus, the nucleus accumbens, and the prefrontal cortex [46]. Afferents of the midline dorsal thalamus originate from the PAG [47], the LC, Barrington's nucleus, the raphe, the parabrachial complex, and the NTS [48]. This connectivity implies that the midline thalamic nuclei are crucial in the central integration of pain perception.

\section{Limbic System}

We found an increased Fos expression in the prelimbic cortex, the infralimbic cortex, the anterior cingulate gyrus, the hypothalamus, and the amygdala after induction of acute inflammatory heart pain in conscious rats. The Fos expression in the cingulate gyrus decreased from rostral to caudal, in line with previous investigations that have implied the role of the rostral human cingulate gyrus in adverse emotional responses to pain [49, 50]. Visceral pain has a stressful effect on rats, and as such is associated with a limbic system-mediated motor response. Accordingly, the main behavioral response types shown during acute heart pain were chest scratching and long-term immobilization. The limbic cortex areas most likely perform functions that are related to the planning and coordination of the behavioral and neuroendocrine stress responses $[50,51]$. A cardiomotor function was demon- 
strated for the anterior cingulate gyrus and for insular cortex [30-32].

The caudal cingulate gyrus has been implicated in the initiation of avoidance reactions that involve attentiondemanding cognitive tasks $[49,50]$. It is tempting to speculate that increased Fos expression in the caudal cingulate cortex represents avoidance-learning behavior in conscious rats. Avoidance responses have a survival value. A typical example of an avoidance reaction to adverse visceral stimulation is the rejection of toxic foods. In humans, pain-inducing coronary artery obstruction(s) or vasospasms can be avoided to some extent. Patients with coronary artery disease will learn an appropriate withdrawal response after repeated attacks. By avoiding stress and exertion, these patients can reduce the intensity and duration of the anginal pain [1].

Increased infralimbic activity after noxious myocardial stimulation may be related to the "visceral motor function' ascribed to this cortical field [52]. Execution of visceral motor activity by the infralimbic cortex involves the hypothalamus, the area that relays the output of the limbic forebrain to the autonomic nervous system [53]. The main output area of the hypothalamus is the paraventricular nucleus [53]. Efferents from the PVN distribute information to the pituitary neuroendocrine system, and the preganglionic parasympathetic and sympathetic cell groups in the brainstem and spinal cord [53, 54]. In stressful situations, the activation of the PVN is important for emotional expression, in particular for the cardiovascular responses.

Cells expressing corticotropin-releasing hormone are located in the PVN and mediate glucocorticoid feedback to the hypothalamo-pituitary-adrenal and limbic system [55]. The central amygdala also controls cardiovascular and neuroendocrine activity $[31,53,56]$ and accordingly showed increased Fos expression after myocardial noxious stimulation. Like the PVN, corticotropin-releasinghormone-positive cells in the central amygdala may exert a glucocorticoid feedback to the limbic forebrain system and the regions involved in modulation of autonomic functions. PET studies showed hypothalamic and hippocampal gyrus (including the amygdala) activation in patients with coronary artery disease during dobutamineinduced heart pain [1,57], confirming increased hypothalamic and amygdaloid Fos expression after induction of acute heart pain in rats.

\section{Descending Pain Control}

The PAG, the LC, and the raphe nuclei all showed an increased Fos expression after the noxious myocardial stimulation. The increase in Fos activity in these centers does not necessarily indicate that these areas are nociceptive receptive centers. c-fos is a marker of neuronal activity which can be activated following different modes of stimuli, including nonnociceptive stimulation [26-32]. In another study in rats, electrical stimulation using TENS (transcutaneous electrical nerve stimulation) showed an increase in c-fos activity in different cardiovascular centers of the brain although the rats which had been stimulated did not show pain behavior [58]. Clinically this mode of stimulation has a beneficial effect on patients with refractory angina pectoris.

Since descending projections from these regions participate in pain modulation [59], the increase in c-fos activity in these areas is most likely related to the descending pain modulation in response to the nociceptive stimulus. Electrical stimulation of the PAG suppresses nociceptionassociated activity of the dorsal horn neurons, including the spinothalamic tract cells $[60,61]$. The PAG is comprised of longitudinally oriented columns with different roles in pain control [62], for example the ventrolateral and lateral PAG, affected most by the noxious myocardial stimulation in awake rats, mediate opioid and nonopioid analgesia, respectively [62]. Descending projections from the LC and raphe nuclei have been associated with socalled gate control [59] - a theory that provides a model to explain modalities of the ascending pain-relaying systems by influencing interneurons at the spinal level, and the flow of information to the pain-processing systems in the forebrain. The raphe magnus has selective 'pain-on' and 'pain-off' cells [63] and innervates, like the LC, the thoracic spinal substantia gelatinosa, and the NTS [59, 64, 65], the regions that receive the input from the cardiac nociceptors. Physical and psychological stress also generate LC and raphe cell activity [66, 67], which may imply the role of stress as a pathophysiological factor in the development of cardiovascular diseases.

\section{Possible Limitation}

Motor behavior was most likely not an important initiator of the Fos expression since the animals, as a consequence of pain perception, remained immobilized most of the time. Accordingly, the Fos expression in the motor cortex and the basal ganglia was not increased after pericardial noxious stimulation.

In conclusion, noxious pericardial stimulation in awake rats is the most realistic angina model available today. It is likely that making use of such models will enable researchers to answer fundamental questions related to the pathways of cardiac pain. 


\section{References}

1 Rosen SD, Paulesu E, Frith CD, Frackowiak SJ, Davies GJ, Jones T, Camici PG: Central nervous pathways mediating angina pectoris. Lancet 1994;344:147-150.

2 Sylven C: Angina pectoris. Clinical characteristics, neurophysiological and molecular mechanisms. Pain 1989;36:145-167.

3 Foreman RD: Mechanisms of cardiac pain. Annu Rev Physiol 1999;61:143-167.

4 Malliani A: Link between transient myocardial ischemia and pain; in Sing BS (ed): Silent Myocardial Ischemia and Angina. New York, Pergamon Press, 1988, pp 34-47.

5 Nedrum T, Baker DJ, Coleridge HM, Coleridge JC: Interaction of bradykinin and prostaglandin $\mathrm{E}_{1}$ on cardiac pressor reflex and sympathetic afferents. Am J Physiol 1986;250:815822.

6 Bolser DC, Chandler MJ, Garrison DW, Foreman RD: Effects of intracardiac bradykinin and capsaicin on spinal and spinoreticular neurons. Am J Physiol 1989;257:1543-1550.

7 De Jongste MJL, Ter Horst GJ: Mediators of inflammation in patients with coronary artery disease; in Ter Horst GJ (ed): The Nervous System and The Heart. Totowa, Humana Press Inc, 2000, pp 467-487.

8 Holzer P: Capsaicin: Cellular targets, mechanisms of action and selectivity for thin sensory neurons. Pharmacol Rev 1991;11:330-343.

9 Szolcsani J: Actions of capsaicin on sensory receptors; in Wood $\mathrm{J}$ (ed): Capsaicin in the Study of Pain. London, Academic Press, 1993 , pp 1-26.

10 Szolcsani J: Capsaicin-sensitive sensory nerves terminals with local and systemic efferent functions: Facts and scopes of the unorthodox neuroregulatory mechanism. Prog Brain Res 1996; 113:343-359.

11 Szolcsanyi J, Oroszi G, Nemeth J, Szilvassy Z, Blasig IE, Tosaki A: Functional and biochemical evidence of capsaicin-induced neural endothelin release in isolated working rat heart. Eur J Pharmacol 2001;419:215-221.

12 Euchner-Wamser I, Meller ST, Gebhart GF: A model of cardiac nociception in chronically instrumented rats: Behavioral and electrophysiological effects of pericardial administration of algogenic substances. Pain 1994;58:117128.

13 Hunt SP, Pini A, Evans G: Induction of c-fos like protein in spinal cord neurons following sensory stimulation. Nature 1987;328:632634.

14 Sagar SM, Sharp FR, Curran T: Expression of c-fos protein in brain: Metabolic mapping at the cellular level. Science 1988;240:13281331.

15 Dragunow M, Faull R: The use of c-fos as a metabolic marker in neuronal pathway tracing. J Neurosci Methods 1989;29:261-265.

16 Anton F, Herdegen T, Peppel P, Leah JD: c-fos-like immunoreactivity in rat brain stem neurons following noxious chemical stimulation of the nasal mucosa. Neuroscience 1991; 41:629-641.
17 Strassman AM, Vos BP: Somatotopic and laminar organization of fos-like immunoreactivity in the medullary and upper cervical dorsal horn induced by noxious fascial stimulation in the rat. J Comp Neurol 1993;331:495-516.

18 Harris JA: Using c-fos as a neural marker of pain. Brain Res Bull 1998;45:1-8.

19 Zimmerman M: Ethical guidelines for investigation of experimental pain in conscious animals. Pain 1983;16:109-110.

20 Kemper RH, Spoelstra MB, Meijler WJ, Ter Horst GJ: Lipopolysaccharide-induced hyperalgesia of intracranial capsaicin sensitive afferents in conscious rats. Pain 1998;78:181-190.

21 Swanson LW: Brain Maps: Computer Graphics Files. Amsterdam, Elsevier, 1992.

22 Pan H, Longhurst JC: Lack of a role of adenosine in activation of ischemically sensitive cardiac sympathetic afferents. Am J Physiol 1995; 269:106-113.

23 Dray A, Dickenson A: Capsaicin, nociception and pain; in Wood $\mathrm{J}$ (ed): Capsaicin in the Study of Pain. London, Academic Press, 1993, pp 239-253.

24 Coleridge HM, Coleridge JC: Cardiovascular afferents involved in regulation of peripheral vessels. Annu Rev Physiol 1980;42:413-427.

25 Lombardi F, Della Bella P, Casati R, Malliani A: Effects of intracoronary administration of bradykinin on the impulse activity of afferent sympathetic unmyelinated fibers with left ventricular endings in the cat. Circ Res 1981;48: 69-75.

26 Clement CI, Keay KA, Owler B, Bandler R: Common patterns of increased and decreased Fos expression in midbrain and pons evoked by noxious deep somatic and noxious visceral manipulations in the rat. J Comp Neurol 1996; 366:495-515.

27 Farkas E, Jansen ASP, Loewy AD: Periaqueductal gray matter input to cardiac-related sympathetic premotor neurons. Brain Res 1998;792:179-192.

28 Keay KA, Clement B, Owler B, Depaulis A, Bandler R: Convergence of deep somatic and visceral nociceptive information onto a discrete ventrolateral midbrain periaqueductal gray region. Neuroscience 1994;61:727-732.

29 Lara JP, Parkes MJ, Silvacarvhalo L, Izzo P, Dawidmilner MS, Spyer KM: Cardiovascular and respiratory effects of stimulation of cell bodies of the parabrachial nuclei in anesthetized rat. J Physiol 1994;477:321-329.

30 Ter Horst GJ, Van den Brink A, Homminga SA, Hautvast RV, Rakhorst G, Mettenleiter T, DeJongste MJ, Lie K, and Korf J: Transneuronal viral labelling of rat heart left ventricle controlling pathways. Neuroreport 1993;4: 1307-1311.

31 Ter Horst GJ, Hautvast R, DeJongste MJ, Korf $\mathrm{J}$ : Neuroanatomy of cardiac activity regulating circuitry: A transneuronal retrograde viral labelling study in the rat. Eur J Neurosci 1996;8: 2029-2041.
32 Ter Horst GJ, Postema F: Forebrain parasympathetic control of heart activity: Retrograde transneuronal viral labeling in rats. Am J Physiol 1997;273:2926-2930.

33 Chan RKW, Sawchenko P: Organization and transmitter specificity of medullary neurons activated by sustained hypertension: Implications for understanding baroreceptor reflex circuitry. J Neurosci 1998;18:371-387.

34 Kuo DC, Oravitz JJ, de Groat WC: Tracing of afferent and efferent pathways in the left inferior cardiac nerve of the cat using retrograde and transport of horseradish peroxidase. Brain Res 1984;321:111-118.

35 Vance WH, Bowker RC: Spinal origins of cardiac afferents from the region of the left anterior descending artery. Brain Res 1983;258:96100.

36 Apkarian AV, Hodge CJ: Primate spinothalamic pathways. 2 . The cells of origin of the dorsolateral and ventral spinothalamic pathways. J Comp Neurol 1989;288:474-492.

37 Hopkins DA, Armour JA: Ganglionic distribution of afferent neurons innervating the canine heart and cardiopulmonary nerves. J Auton Nerv Syst 1989;26:213-222.

38 Ammons WS, Blair RW, Foreman RD: Greater splanchnic excitation of primate $T_{1}-T_{5}$ spinothalamic neurons. J Neurophysiol 1984;51: 592-603.

39 Ammons WS, Girardot MN, Foreman RD: Ef fects of intracardiac bradykinin on $\mathrm{T}_{1}-\mathrm{T}_{5}$ medial spinothalamic cells. Am J Physiol 1985; 249:147-152.

40 Lenz FA, Gracely RH, Hope EJ, Baker F, Rowland LH, Dougherty PM, Richardson RT: The sensation of angina can be evoked by stimulation of the human thalamus. Pain 1994;59: 119-125.

41 Oppenheimer SM, Kulshreshtha N, Lenz FA, Zhang Z, Rowland LH, Dougherty P: Distribution of cardiovascular related cells in the human thalamus. Clin Auton Res 1989;8:173179.

42 Allen GV, Saper CB, Hurley KM, Cechetto D: Organization of visceral and limbic connections in the insular cortex of the rat. J Comp Neurol 1991;311:1-16.

43 Cechetto DF, Saper CB: Evidence for a viscerotopic sensory representation in the cortex and thalamus in the rat. J Comp Neurol 1987;262: 27-45.

44 Takada M: Widespread dopaminergic projections of the subparafascicular thalamic nucleus in the rat. Brain Res Bull 1993;32:301-309.

45 Yasui Y, Nakano K, Mizuno N: Descending projections from the subparafascicular thalamic nucleus to the brainstem in the rat. Exp Brain Res 1992;90:508-518.

$46 \mathrm{Su}$ HS, Bentivoglio M: Thalamic midline cell populations projecting to the nucleus accumbens, amygdala, and hippocampus in the rat. $\mathrm{J}$ Comp Neurol 1990;297:582-593. 
47 Cameron A, Khan IA, Westlund KN, Cliffer $\mathrm{KD}$, Willis W: The efferent projections of the periaqueductal gray in the rat: A Phaseolus vulgaris-leucoagglutinin study. 1. Ascending projections. J Comp Neurol 1995;351:568-584.

48 Otake K, Nakamura Y: Single neurons in Barrington's nucleus projecting to both the paraventricular thalamic nucleus and the spinal cord by way of axon collaterals: A double labeling study in the rat. Neurosci Lett 1996;209: 97-100.

49 Davis KD, Taylor S, Crawley AP, Wood M, Mikulis D: Functional MRI of pain- and attention-related activations in the human cingulate cortex. J Neurophysiol 1997;77:3370-3380.

50 Sullivan RM, Gratton A: Lateralized effects of medial prefrontal cortex lesions on neuroendocrine and autonomic stress responses in rats. J Neurosci 1999; 19:2834-2840.

51 Devinsky O, Morrell MJ, Vogt BA: Contributions of anterior cingulate cortex to behaviour. Brain 1995;118:279-306.

52 Takagishi M, Chiba T: Efferent projections of the infralimbic (area 25) region of the medial prefrontal cortex in the rat: An anterograde PHA-L study. Brain Res 1991;566:26-39.

53 Luiten PG, Ter Horst GJ, Steffens AB: The hypothalamus, intrinsic connections and outflow pathways to the endocrine system in relation to the control of feeding and metabolism. Prog Neurobiol 1987;28:1-54.
54 Saper CB: Central autonomic nervous system; in Paxinos G (ed): The Rat Nervous System, ed 2. San Diego, Academic Press, 1995, pp 107135 .

55 Sawchenko PE, Swanson LW: Organization of $\mathrm{CRF}$ immunoreactive cells and fibers in the rat brain: Immunohistochemical studies; in Souza EB, Nemeroff CB (eds): Corticotropin-Releasing Factor: Basic and Clinical Studies of a Neuropeptide. Boca Raton, CRC Press Inc, 1990, pp 29-52.

56 Ter Horst GJ: Emotions and heart-activity control; in Ter Horst GJ (ed): The Nervous System and The Heart. Totowa, Humana Press Inc, 2000, pp 55-116.

57 Rosen SD, Paulesu E, Nihoyannopoulos P, Tousoulis D, Frackowiak RS, Frith CD, Jones T, Camici PG: Silent ischemia as a central problem: Regional brain activation compared in silent and painful myocardial ischemia. Ann Intern Med 1996;124:939-949.

58 Albutaihi IAM, DeJongste MJL, Ter Horst GJ: Cardiac nociception in rats; Neuronal pathways and the influence of dermal neurostimulation on conveyance to the central nervous system. J Mol Neurosci 2003;20:43-52.

59 Stamford JA: Descending control of pain. Br J Anaesth 1995;75:217-227.

60 Besson JM, Chaouch A: Peripheral and spinal mechanisms of nociception. Physiol Rev 1987; 67:67-186.
61 Gerhart KD, Yeziersky RP, Wilcox TK, Willis WD: Inhibition of primate spinothalamic tract neurons by stimulation of the periaqueductal gray or adjacent midbrain reticular formation. J Neurophysiol 1984;51:450-466.

62 Bandler R, Shipley MT: Columnar organization of the midbrain periaqueductal gray: Modules for emotional expression? Trends Neurosci 1994;17:379-384.

63 Leung CG, Mason P: Physiological survey of medullary raphe and magnocellular reticular neurons in the anesthetized rat. J Neurophysiol 1998;80:1630-1646.

64 Aston-Jones G, Shipley MT, Grzanna R: The locus coeruleus, A5 and A7 noradrenergic cell groups; in Paxinos G (ed): The Rat Nervous System, ed 2. San Diego, Academic Press, 1995, pp 183-213.

65 Sim LJ, Joseph SA: Efferent projections of the nucleus raphe magnus. Brain Res Bull 1992;28: 679-682.

66 Martinez M, Phillips P, Herbert J: Adaptation in patterns of c-fos expression in the brain associated with exposure to either single or repeated social stress in male rats. Eur J Neurosci 1998;10:20-33.

67 Ishida Y, Hashiguchi H, Takeda R, Ishizuka Y, Mitsuyama Y, Kannan H, Nishimori T, Nakahara D: Conditioned-fear stress increases Fos expression in monoaminergic and GABAergic neurons of the locus coeruleus and dorsal raphe nuclei. Synapse 2002;45:46-51. 